\title{
NATURE OR NuRTURE? \\ Learning and Female Labor Force Dynamics
}

\author{
AlessandRa Fogli* \\ Minneapolis Federal Reserve \\ NYU and CEPR
}

\author{
LAURA VELDKAMP \\ New York University \\ Stern School of Business
}

First version: February 2007

This version: May 1, 2007

\begin{abstract}
Much of the increase in female labor force participation in the post-war period has come from the entry of married women with young children. Accompanying this change has been a rise in cultural acceptance of maternal employment. We argue that the concurrent S-shaped rise in maternal participation and its cultural acceptance is well explained by generations of women engaged in Bayesian learning about the effects of maternal employment on children. Each generation updates their parents' beliefs by observing the children of employed women. When few women participate in the labor force, most observations are uninformative and participation rises slowly. As information accumulates and the effects of labor force participation become less uncertain, more women participate, learning accelerates and labor force participation rises faster. As beliefs converge to the truth, participation flattens out. Survey data, wage data and participation data support our mechanism and distinguish it from alternative explanations.
\end{abstract}

${ }^{*}$ Corresponding author: afogli@stern.nyu.edu, Research Department Federal Reserve Bank of Minneapolis, 90 Hennepin Ave. Minneapolis, MN 55401. We thank seminar and conference participants at Chicago GSB, Wisconsin Madison, Midwest Macro Meetings, the Minneapolis Federal Reserve and Princeton. We especially thank Stefania Marcassa for excellent research assistance and Larry Jones and Patrick Kehoe for comments and suggestions. Laura Veldkamp thanks Princeton University for their hospitality and financial support through the Kenen fellowship. Keywords: female labor force participation, preference formation, S-shaped learning, labor supply, endogenous information diffusion. JEL codes: J21, N32, R12, Z13. 
One of the most dramatic economic changes of the last century has been the rise in female labor force participation. Central to this rise has been the entry of married women with young children. While only $6 \%$ of the mothers of preschool age children worked in the labor market in $1940,60 \%$ of these mothers are employed today. This phenomenon took place at the same time as a radical cultural change in the social acceptability of maternal employment. In just the last three decades, the fraction of people who report that a preschool child is likely to suffer if her mother works, has fallen by almost one-half. A large empirical literature has argued that such attitudes and beliefs, broadly defined as culture, are an important determinant of labor force participation. ${ }^{1}$ We investigate where these cultural beliefs come from and how they interact with the labor force participation decisions of women with young children.

We argue that beliefs are formed and evolve over time as women learn about the relative importance of nature (innate ability) and nurture (the role of maternal employment) in determining children's outcomes. A crucial factor in a woman's choice to work is the effect of her employment on her children. The extent to which labor force participation trades off with children's future utility is unknown. Women pass down beliefs about the importance of nurture to their children. Each generation updates those beliefs, using a set of observations on other children's outcomes. However, observations are only informative about the cost of labor force participation if women in the previous generation work. Initially, very few women participate in the labor market; information about the role of nurture diffuses slowly and beliefs are nearly constant. As information accumulates and the effects of labor force participation become less uncertain, more women participate, learning accelerates and labor force participation rises more quickly. As beliefs converge to the truth, learning slows down and participation flattens out. This interaction between beliefs and participation generates a simultaneous S-shaped evolution of women's beliefs and of labor force participation that mimics the data from the past century.

Why explore a learning explanation when existing theories based on technological innovation, falling child care costs, the less physical nature of jobs and increases in women's wages have had

\footnotetext{
${ }^{1}$ See Fernández and Fogli (2005), Fernández, Fogli, and Olivetti (2002), Fortin (2005), Alesina and Giuliano (2007).
} 
success in explaining features of participation? ${ }^{2}$ First, cultural change itself is economically important (Giuliano (2007), Guiso, Sapienza, and Zingales (2004) and Barro and McCleary (2006)). While Bisin and Verdier (2000) and Doepke and Zilibotti (2007) have modeled culture as a feature of preferences, we develop a model of cultural change based on Bayesian learning. Second, the existing theories rely on some, often unstated, assumptions about what agents know and believe. For example, a model where a new technology enables a woman to complete housework and pursue a career typically assumes that the woman is aware of the technology, knows its effect on her productivity, and understands the effect on her children of outsourcing their care. This model examines those kinds of informational assumptions. Third, adding learning allows the model to reconcile a broad set of facts about participation dynamics, cross-sectional differences in female participation, labor supply elasticity and reported beliefs, that other theories to not.

As a theoretical contribution, the model fills a gap between the literature on S-shaped learning dynamics and that on endogenous information. The S-shaped learning dynamic is similar to Amador and Weill's (2006) model where agents, arranged on a lattice, learn what their neighbors know. But rather than studying the spread of information that agents are endowed with, we study an environment where information is revealed only if a woman works. The fact that information and actions are mutually interdependent delivers additional testable predictions. Not only do beliefs predict actions, as in exogenous information models, but actions also predict changes in beliefs. This idea that information is a by-product of economic activity appears in Van Nieuwerburgh and Veldkamp (2006). But there was no S-shaped learning dynamic. Because the variable being learned about was constantly changing, beliefs did not converge. Combining these two sets of ideas generates new predictions that are supported by data.

Over the last century, female labor force participation and beliefs about the welfare of children with working mothers have risen concurrently, following an S-shaped time path. Section 1 establishes this fact and presents evidence on the two key ingredients of our story: The change in the labor supply of married women with small children has been a major factor in the rise of aggre-

\footnotetext{
${ }^{2}$ See Greenwood, Seshadri, and Yorukoglu (2001), Goldin and Katz (2002), and Albanesi and Olivetti (2006) on technologies, Attanasio, Low, and Sanchez-Marcos (2006) on child care costs, and Goldin (1990), Jones, Manuelli, and McGrattan (2003) on nature of jobs.
} 
gate female labor force; and there is great uncertainty about the effect of maternal employment on children.

Section 2 develops an overlapping generation model where a woman faces a trade-off between enjoying more consumption if she enters the labor force and earns a wage, and staying out of the labor force to nurture her children and ensure they have high future utility. Women use Bayesian updating to learn about the importance of maternal employment in determining children's outcomes. The results (section 3) show how two competing forces speed up, then slow down learning, creating the S-shaped participation dynamic. Learning is slow at first because few women work, making data about labor force participation scarce. As women learn, participation increases and speeds up learning. The offsetting force is that as beliefs become more informed, new information affects them less. We also show that, as learning converges, labor force participation becomes less responsive to wages, a feature of recent data (Blau and Kahn 2005).

To evaluate the quantitative predictions of the model, sections 4 and 5 use moments of the labor force participation data and the distribution of wages from the census to calibrate and simulate a dynamic learning model. We compare participation rates, survey responses, wages and endowments predicted by the model to the data. The simulated time path of labor force participation looks strikingly similar to the data, slightly over-predicting the increase. When we ask agents in our model the questions from our survey data, their replies match the level and evolution of the actual survey responses. Finally, wages and endowments of working women change over time in the model because of a selection effect: The women who choose to work is changing. For endowments, the model under-predicts their level but matches the size of their increase. For wages, the model matches the data well until 1980. At that point, wages rise suddenly, in the data, but not in the model. We show that adding a high-intensity occupation that has a higher and more uncertain toll on children, but offers higher wages, can match the increase in women's wage.

Section 6 evaluates other testable implications of our learning model for belief dispersion, wage elasticity, history dependence of participation decisions, and the change in survey responses over the life-cycle. In section 7 , we use these predictions to distinguish our learning theory from other competing explanations. Section 8 concludes. 


\section{Motivating Facts: Beliefs, Participation and Child Development}

Before proceeding with our theory, we document the rise in labor force participation and the cultural change we are building the theory to explain. We also establish support for a critical assumption of our model, that the effects of maternal employment on children is uncertain.

\subsection{Employment increase of women with young children}

The bulk of the increase in labor force participation came from married women with children. Single mothers and women without children started with much higher participation rates, which increased, but not dramatically. In contrast, the participation of married women with children increased by more than three-fold. Even among this subgroup, the largest increase came from women with children under 5 years of age. The participation rate for this group was $6 \%$ in 1940 and rose almost 10 -fold to $59 \%$ in 2004 . For this reason, we focus our theory on the concerns and trade-offs that women with children face. The rest of our data analysis will pertain to the group of women whose labor force participation showed the most change over the last century: married women, with children under 5 years of age.

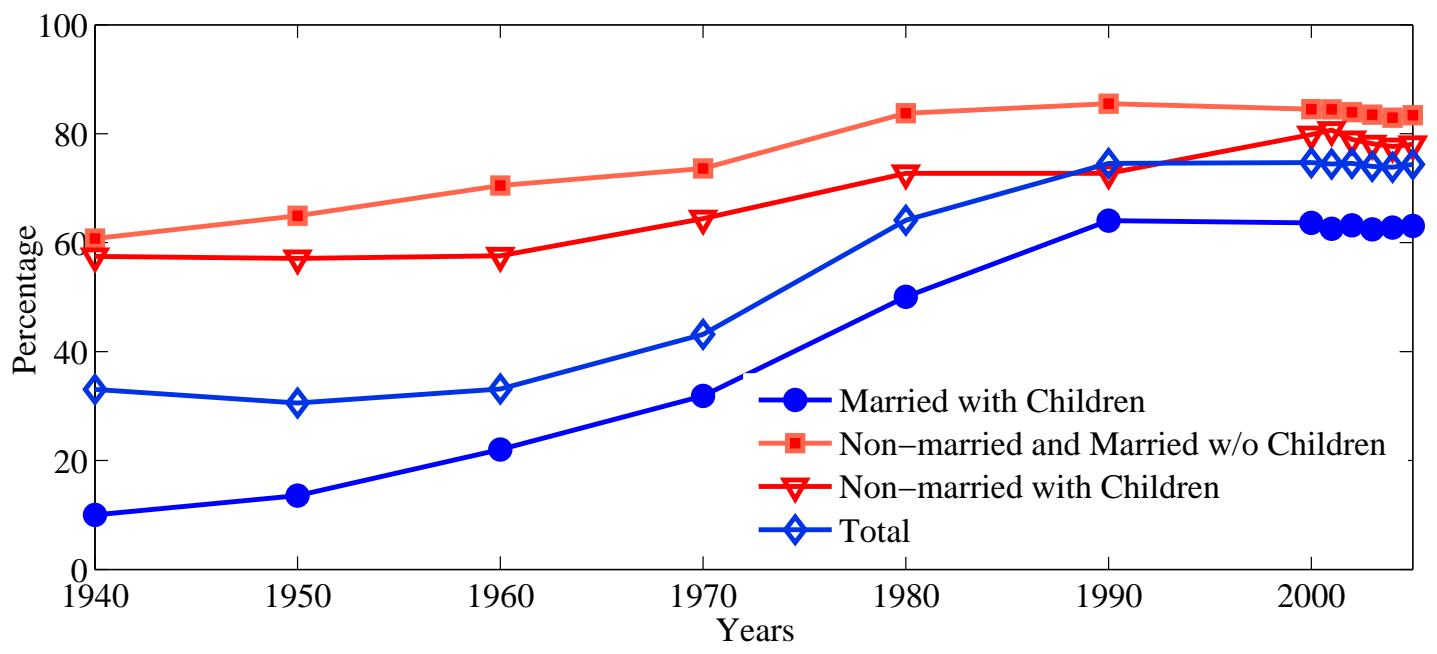

Figure 1: LABOR FORCE PARTICIPATION AMONG SUB-GROUPS OF WOMEN. Details of the data are in appendix B. 


\subsection{Change in beliefs}

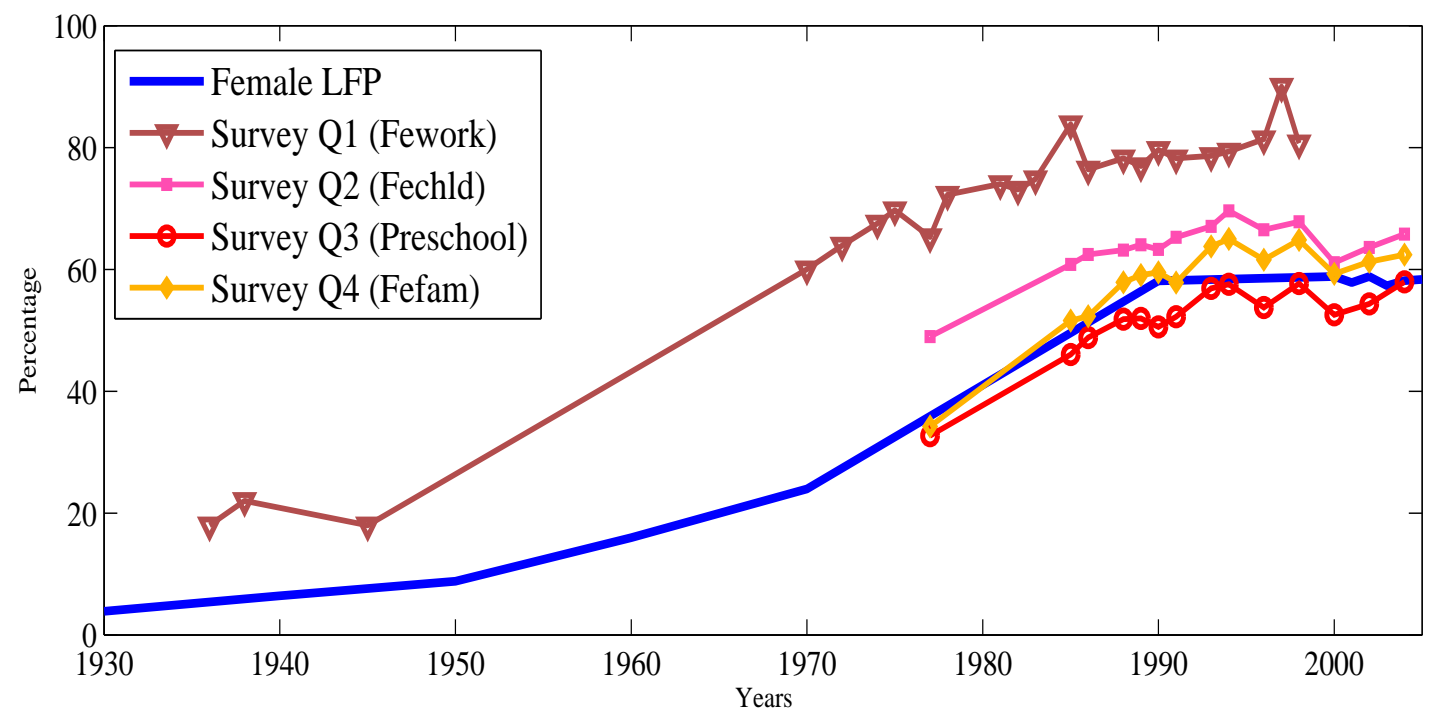

Figure 2: LABOR FORCE PARTICIPATION AND AVERAGE SURVEY RESPONSES.

Survey questions are about the effect of women's labor force participation on children. Appendix B states each question. A higher level indicates a more favorable attitude toward participation.

One of the reasons to think that the main force is changes in beliefs about the effect of market work on children is survey evidence revealing that such beliefs have changed. The survey questions are about whether a married woman should work (fework), whether she compromises her relationship with her children (fechld), whether pre-school age children, in particular, suffer (preschool), and whether her family suffers (fefam). (Data details in appendix B.) Figure 2 plots labor force participation and survey answers, from 1930-2005. The fact that the survey responses are increasing in their average level indicates that, over time, people believe that women's labor force participation is less harmful to their families. What is striking about this graph is that the labor force participation tracks the survey responses so closely and that both display an S shape. Greater participation and cultural change are highly correlated.

Data from surveys that ask specifically about employment in various stages of women's lifecycle show that the presence of a small child is crucial in determining attitudes. Since we have these data only in 1988, 1994 and 2002, we pool the three years. When asked if a woman should work 
full time outside the home after marrying and before there are children, $70 \%$ say yes. But when that woman has an infant, support falls to 10\%. (See appendix B for data details.) Whatever is determining beliefs about the costs and benefits of labor force participation is not something that affects all women equally. It hinges crucially on the presence of children.

\subsection{Psychological evidence on the true value of nurture}

Our theory is based on the premise that the effect of mothers' employment on children is uncertain. This is a reasonable assumption because even academic psychologists have not reached a consensus. Harvey (1999) summarizes studies that started in the early 60s and flourished in the 1980s when the children of the women interviewed in the National Longitudinal Survey of Youth (NLSY) reached adulthood. Six different published studies have used the NLSY to examine the longitudinal effects of early maternal employment on children's development, controlling for various family background variables. Harvey compares these studies and concludes that "their results have been surprisingly mixed." Her analysis of the data indicates that working more hours is associated with slightly lower cognitive development through age 9 and slightly lower academic achievement scores before age 7 .

A more recent study by Hill, Waldfogel, Brooks-Gunn, and Han (2005) finds small but significant negative effects of maternal employment on children's cognitive outcomes for full-time employment in the first year post-birth as compared with employment postponed until after the 1st year. Bernal and Keane (2006) concur: Having a full-time working mother who uses informal child care during one of the first five years after childbirth is associated with a 3.4 percent reduction in the child's

test score. Belsky (1988) also finds that maternal employment is detrimental: Infants who were in non maternal care for more than 20 hours per week were at elevated risk for being insecurely attached at age 1 and were more aggressive and disobedient between ages 3 and 8 . In sum, while there is little evidence of negative effects of maternal employment when children are older, there is substantial debate about the size of the effects of maternal employment in early childhood. 


\section{The Model}

We assume a discrete infinite horizon, $t=1,2, \ldots$, and we consider an overlapping generation economy made up of a large finite number of agents living for two periods. Each agent is nurtured in the first period and consumes and has one child in the second period of her life. Preferences of an individual in family $i$ born at time $t-1$ depend on their consumption $c_{i t}$ and the potential wage of their child $w_{i, t+1}$.

$$
U=\frac{c_{i t}^{1-\gamma}}{1-\gamma}+\beta \frac{w_{i, t+1}^{1-\gamma}}{1-\gamma} \quad \gamma>1
$$

This utility function captures the idea that parents care about their child's potential, but not the choices they make. This shuts down an experimentation motive where mothers participate in order to create information that their decedents can observe. Such a motive makes the problem both intractable and unrealistic. Responsible parents do not gamble with their children's future just to observe what happens.

The budget constraint of the individual from family $i$ born at time $t-1$ is

$$
c_{i t}=n_{i t} w_{i t}+\omega_{i t}
$$

where $\omega_{i t}$ is an endowment which could represent a spouse's income and $n_{i t} \in\{0,1\}$ is the discrete labor force participation choice. If the agent works in the labor force, $n_{i t}=1$.

The key feature of the model is that an individual's earning potential is determined by a combination of endowed ability and nurturing, that cannot be perfectly disentangled. Endowed

ability is an unobserved normal random variable $a_{i, t} \sim N\left(\mu_{a}, \sigma_{a}^{2}\right)$. If a mother stays home with her child, the child's full natural ability is achieved. If the mother joins the labor force, some unknown amount $\theta$ of the child's ability will be lost. Wages depend exponentially on ability:

$$
w_{i, t}=\exp \left(a_{i, t}-n_{i, t-1} \theta\right)
$$


Information Sets The constant $\theta$ determines the importance of nurture and is not known when making labor supply decisions. Young agents inherit their prior beliefs about $\theta$ from their parents' beliefs. In the first generation, initial beliefs are $\theta_{i, 0} \sim N\left(\mu_{0}, \sigma_{0}^{2}\right)$. Each subsequent generation updates these beliefs by observing w's. But, their signals are only informative about the effect of maternal employment on wages if a mother actually worked. Note from equation (3) that if $n_{i, t-1}=0$, then $w_{i, t}$ is only reflecting innate ability and contains no information about $\theta$.

Each agent knows whether she was nurtured $n_{i, t-1}$ and observes her potential wage $w_{i, t}$ at the beginning of time $t$. We refer to $w$ as the potential wage because it is observed, regardless of whether the agent chooses to work. ${ }^{3}$ In addition, she observes both potential earnings and parental employment decisions for $J$ peers, randomly and independently chosen from the population. Ability $a$ is never observed so that $\theta$ can never be perfectly inferred from the wage. The set of family indices for the outcomes observed by agent $i$ is $\mathbb{J}_{i}$. Agents use the information in observed potential wages to update their prior, according to Bayes' law.

Bayesian updating with $J$ signals is equivalent to running a regression of children's potential wages on parents' labor choices and then forming a linear combination of the estimated weight on labor choices $\hat{\theta}$ and the prior belief $\mu_{t}$. Figure 3 shows the timing of information revelation and decision-making.

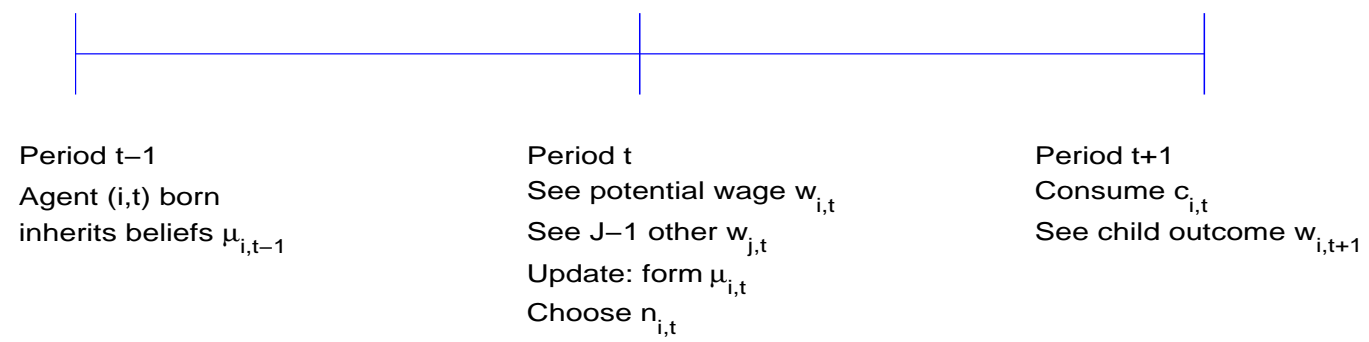

Figure 3: MOdel TIMING.

\footnotetext{
${ }^{3}$ This assumption could be relaxed. If $w_{i, t}$ were only observed once agent (i,t) decided to work, then an informative signal about $\theta$ would only be observed if both $n_{i, t}=1$ and $n_{i, t-1}=1$. Since this condition is satisfied less frequently, such a model would make fewer signals observed and make learning slower.
} 
At the end of each period $t$, the regression agents run to form their signal is

$$
W-\mu_{a}=N \theta+\varepsilon_{i}
$$

where $W$ and $N$ are $J \times 1$ vectors $\left\{\log w_{j, t}\right\}_{j \in \mathbb{J}_{i}}$ and $\left\{n_{i, t-1}\right\}_{j \in \mathbb{J}_{i}}$. Let $\bar{n}_{i, t}$ be the sum of the labor decisions for the set of families that $(i, t)$ observes: $\bar{n}_{i, t}=\sum_{j \in \mathbb{J}_{i}} n_{i, t}$. The resulting estimated coefficient $\hat{\theta}$ is normally distributed with mean $\hat{\mu}_{i, t}=\sum_{j \in \mathbb{J}_{i}}\left(\log w_{j, t}-\mu_{a}\right) n_{j, t} / \bar{n}_{i, t}$ and variance $\hat{\sigma}_{i, t}^{2}=\sigma_{a}^{2} / \bar{n}_{i, t}$.

Posterior beliefs about the value of nurturing are normally distributed $\theta \sim N\left(\mu_{i, t}, \sigma_{i, t}^{2}\right)$. The posterior mean is a linear combination of the estimated coefficient and the prior beliefs, where each component's weight is its relative precision:

$$
\mu_{i, t}=\frac{\hat{\sigma}_{i, t}^{2}}{\sigma_{i, t-1}^{2}+\hat{\sigma}_{i, t}^{2}} \mu_{i, t-1}+\frac{\sigma_{i, t-1}^{2}}{\sigma_{i, t}^{2}+\hat{\sigma}_{i, t}^{2}} \hat{\mu}_{i, t}
$$

The posterior precision (inverse of the variance) is the sum of the prior precision and the signal precision. Thus posterior variance is

$$
\sigma_{i, t}^{2}=\left(\sigma_{i, t-1}^{-2}+\hat{\sigma}_{i, t}^{-2}\right)^{-1}
$$

Definition of equilibrium An equilibrium is a sequence of wages, distributions that characterize beliefs about $\theta$, work and consumption choices, for each individual $i$ in each generation $t$ such that:

1. Taking beliefs and wages as given, consumption and labor decisions maximize expected utility (1) subject to the budget constraint (2).

2. Wages of agents born in period $t-1$ are consistent with the labor choice of the parents, as in $(3)$.

3. An agent $i$ born at date $t-1$ chooses consumption and labor at date $t$. That optimization is conditioned on beliefs $\mu_{i, t}, \sigma_{i, t}$.

4. Priors $\mu_{i, t-1}, \sigma_{i, t-1}$ are equal to the posterior beliefs of the parent, born at $t-1$. Priors are 
updated using observed wage outcomes $\mathbb{J}_{i, t}$, according to Bayes' law (4).

5. Distributions of elements $\mathbb{J}_{i, t}$ are consistent with distribution of optimal labor choices $n_{i,(t-1)}$.

\section{Results}

Substituting the budget constraint (2) and the law of motion for wages (3) into expected utility (1) produces the following optimization problem for agent $i$ born at date $t-1$ :

$$
\max _{n_{i t} \epsilon\{0,1\}} \frac{\left(n_{i t} w_{i t}+\omega_{i t}\right)^{1-\gamma}}{1-\gamma}+\beta E_{a_{i, t+1}, \theta}\left[\frac{\exp \left(\left(a_{i, t+1}-n_{i, t} \theta\right)(1-\gamma)\right)}{1-\gamma}\right] .
$$

Taking the expectation over the unknown ability $a$ and the importance of nurture $\theta$ delivers expected utilities from each choice. If a woman stays out of the labor force, her expected utility is

$$
E U O_{i t}=\frac{\left(\omega_{i t}\right)^{1-\gamma}}{1-\gamma}+\frac{\beta}{1-\gamma} \exp \left(\mu_{a}(1-\gamma)+\frac{1}{2} \sigma_{a}^{2}(1-\gamma)^{2}\right)
$$

If she participates in the labor force, her expected utility is

$$
E U W_{i t}=\frac{\left(w_{i t}+\omega_{i t}\right)^{1-\gamma}}{1-\gamma}+\frac{\beta}{1-\gamma} \exp \left(\left(\mu_{a}-\mu_{i, t}\right)(1-\gamma)+\frac{1}{2}\left(\sigma_{a}^{2}+\sigma_{i, t}^{2}\right)(1-\gamma)^{2}\right)
$$

The optimal policy is to join the labor force when the expected utility from employment is greater than the expected utility from staying home $\left(E U W_{i t}>E U O_{i t}\right)$. Define $\mathcal{N}_{i t} \equiv E U W_{i t}-E U O_{i t}$ to be the expected net benefit of labor force participation, conditional on time $t$ information $\left(\mu_{i, t}, \sigma_{i, t}\right)$.

\subsection{The Role of Beliefs in Labor Force Participation}

We begin by establishing some intuitive properties of the labor force participation decision rule. Women who think nurture is more important and those who are more uncertain about the importance of nurture are less likely to work.

Proposition 1 A higher expected value of nurture reduces the probability that a woman will participate in the labor force, holding all else equal. 
Proof: in appendix A.1. The logic of this result can be seen in equation (8). Increasing the expected value of nurture decreases the net expected utility of labor force participation: $\partial \mathcal{N}_{i, t} / \partial \mu_{i, t}=-\beta$, times an term which is an exponential and thus must be non-negative. Since $-\beta<0$, a higher $\mu_{i, t}$ reduces the utility gain from labor force participation and therefore reduces the probability that a woman will participate.

Proposition 2 Greater uncertainty about the value of nurture reduces the probability that a woman will participate in the labor force, holding all else equal.

Proof: in appendix A.2. Again, the logic of the result is in the fact that the benefit to working is falling in uncertainty: $\partial \mathcal{N}_{i, t} / \partial \sigma_{i, t}=(1-\gamma) \beta$, times an term which is an exponential and thus must be non-negative. Since $\gamma>1$, then $(1-\gamma) \beta<0$, meaning that more uncertainty reduces the probability a woman will participate.

\subsection{S-shaped Learning Dynamics}

The model generates an S-shaped pattern of labor force participation because beliefs about the cost of participation move slowly at first, then faster, and then slow down. There are two competing forces that generate this dynamic. One force is that as the number of women in the labor force increases, the average sized revision in beliefs increases. The second, competing force is that as beliefs converge to the truth, revisions in beliefs become smaller.

The information gleaned from observing others' labor market outcomes can be described as a signal with mean $\hat{\mu}_{i, t}=\sum_{j \in \mathbb{J}_{i}}\left(\log w_{j, t}-\mu_{a}\right) n_{j, t} / \bar{n}_{i, t}$ and variance $\hat{\sigma}_{i, t}^{2}=\sigma_{a}^{2} / \bar{n}_{i, t}$. Let $\rho$ be the fraction of women who participate in the labor force. Then, the expected precision of this signal is $E\left[\hat{\sigma}_{i, t}^{-2}\right]=\rho N \sigma_{a}^{2}$.

A higher signal precision increases the expected size of squared changes in beliefs. This conditional variance of $t$ beliefs, conditional on period $t-1$ beliefs is the difference between prior variance and posterior variance: $\operatorname{var}\left(\mu_{i, t} \mid \mu_{i, t-1}\right)=\sigma_{i, t-1}^{2}-\sigma_{i, t}^{2}$. Substituting in for posterior variance (5),

$$
\operatorname{var}\left(\mu_{i, t} \mid \mu_{i, t-1}\right)=\sigma_{i, t-1}^{2}-\frac{1}{\sigma_{i, t-1}^{-2}+\hat{\sigma}_{i, t}^{-2}}
$$


Since $\partial \operatorname{var}\left(\mu_{i, t} \mid \mu_{i, t-1}\right) / \partial \hat{\sigma}_{i, t}^{-2}>0$, the expected size of revisions is increasing in the precision of the observed signals. For the average agent, this precision is increasing in the fraction of women who work. This is the first force as work that increases the rate of learning over time and causes the labor force participation rate to increase at an increasing rate, early in the century.

The second force is the convergence or beliefs to the truth. Over time, the variance of beliefs about $\theta$ declines. This effect can be seen in the posterior variance formula (5). If there is no information in any of the observed labor market outcomes, then $\sigma_{i, t}^{2}=\sigma_{i, t-1}^{2}$. Given any new information, $\hat{\sigma}_{i, t}^{-2}>0$, posterior variance is lower than in the previous period: $\sigma_{i, t}^{2}<\sigma_{i, t-1}^{2}$. As $\sigma^{2}$ falls, the conditional variance of changes in beliefs falls as well: $\partial v a r / \partial \sigma_{i, t-1}^{2}>0$.

The increase in signal quality early on in the century was the dominant force, causing learning to speed up. This effect diminished later on because the convergence of beliefs to the truth reduces the effect of higher signal precision. This effect is about the cross-partial derivative: $\partial^{2} \operatorname{var} / \partial \hat{\sigma}_{i, t}^{-2} \partial \sigma_{i, t-1}^{-2}=-2 /\left(\sigma_{i, t-1}^{-2}+\hat{\sigma}_{i, t}^{-2}\right)^{3}<0$. The convergence of beliefs is the dominant force, slowing down learning later in the century both because higher prior precision makes belief revisions smaller and because higher prior precision reduces the effect of more informative signals.

What starts the transition? The discussion of labor force participation dynamics raises the question of how this dynamic transition started and why it started in the early 20th century. The shift from agriculture to industrialization at the end of the 19th century changed the nature of work. In agriculture, women allocated time continuously between work and child-rearing. This was possible because home and work were in the same location. Industrialization required women who took jobs to outsource their child care. Only at that stage did people start to ask what effects outsourcing has on children.

If no women initially participated in industrial era employment and therefore no information was being generated about the effects of maternal employment, one might worry that such a situation might be an absorbing state. The following proposition (proven in appendix A.3) shows that zero labor force participation is not a steady state.

Proposition 3 In any period where the labor force participation rate is zero $\left(\sum_{j} n_{j, t-1}=0\right)$, there 
is a positive probability that at least one woman will work in the following period $\left(\sum_{j} n_{j, t} \geq 1\right)$.

Zero participation is a state that can persist for many periods and is exited each period with a small probability. All it takes to escape a zero-participation state is for one extremely able woman to be born. For a sufficiently able woman, working will be optimal, despite the uncertainty and pessimism about the effect of working on her children.

Condition (8) also suggests circumstances in which such a woman is likely to emerge. When the endowment $\omega_{j t}$ is low, the cutoff ability level $a^{*}$ will be lower because the marginal value of women's income is higher. Thus, in times like the great depression or wars when husbands' incomes are lost, or when technologies reduce the cost of participation, the probability that a woman would be sufficiently able to work rises. Thus, existing theories can provide a shock that sparks the transition. But such exogenous shocks are not necessary for the transition to occur.

\subsection{Additional Testable Predictions}

To determine whether learning is playing a role in female labor force participation, we need to derive indirect predictions of the model. Later, we use these predictions to empirically distinguish learning from other potential explanations.

\subsubsection{The Effect of Wealth}

An alternative explanation for the flattening out of women's labor force participation is that women participate less when their wealth level is higher. This force is present in the model.

Proposition 4 Greater initial wealth $\omega_{i, t}$ reduces the probability that a woman will participate in the labor force, holding all else equal.

Proof in appendix A.4. The effect of wealth on the value of participating in the labor force is $\partial \mathcal{N}_{i, t} / \partial \omega_{i, t}=\left(w_{i, t}+\omega_{i, t}\right)^{-\gamma}-\left(\omega_{i, t}\right)^{-\gamma}$. This is negative because $\left(w_{i, t}+\omega_{i, t}\right)>\left(\omega_{i, t}\right)$ holds with probability one. This means that more wealth reduces the utility gain from labor force participation. 


\subsubsection{Learning and Labor Supply Elasticity}

The wage elasticity of the labor supply is the marginal change in the log probability that a woman participates due to a log change in the average wage. Since wages make working more attractive, this elasticity is always positive. However, it declines as women learn more about the effects of labor force participation on their children. (Proof in appendix A.5.)

Proposition 5 As uncertainty about the value of nurture falls, the wage elasticity of an individual's labor force participation declines: $\partial^{2} \ln \left(\operatorname{Prob}\left(\mathcal{N}_{i, t}>0\right)\right) / \partial \sigma_{i, t}^{2} \partial \ln \left(\operatorname{mean}\left(w_{i, t}\right)\right)>0, \forall(i, t)$.

Changing the average wage has two effects, each of which interacts with uncertainty. There is a direct effect on the benefit of working and an indirect effect on the expected wage of children. The direct effect of a decrease in uncertainty is to reduce the cutoff wage required to induce a woman to work. The elasticity of labor supply is equal to the hazard function of the wage distribution, evaluated at the cutoff wage. Therefore, a reduction in the cutoff value means a lower value for the hazard function and a lower elasticity. More intuitively, when uncertainty is low, more women are already in the labor force and have wages far above the cutoff wage. The density of women with wages near the cutoff wage is small. Therefore, proportional changes in the wage have a small effect on the number of women who work, when uncertainty is low.

The indirect effect is that an increase in the average wage makes mothers expect a higher income for their children as well. Higher income diminishes the marginal utility cost of reducing the child's future income by working (utility is concave). This lowers the cutoff wage, making more women participate. Uncertainty amplifies the effect of a higher average child's wage on this cutoff. Our utility function is such that agents are more averse to risk when wage realizations are low than when they are high. Therefore, they are much more responsive to a changes in the probability of catastrophic outcomes than to average or excellent ones. When uncertainty increases, the probability of extreme outcomes rises. When more probability is placed on the catastrophic outcomes, agents become more sensitive to changes in the average wage. The higher probability of excellent outcomes reduces their sensitivity, but by less. Therefore, when uncertainty increases, this net increased sensitivity to changes in the average wage causes the elasticity of labor supply 
to rise. Since both the direct and the indirect effect cause elasticity to increase with uncertainty, as learning resolves uncertainty over time, the labor supply elasticity falls.

\subsubsection{Survey responses in the model}

One of the dimensions along which we will evaluate our model is to compare its predictions for beliefs about the value of labor force participation to survey data about whether mothers should participate in the labor force. To do this, we need a precise mapping between the survey responses and model quantities. We establish this mapping by asking agents in our model whether they believe, based on their observed information, that the average household's utility $U$ would be higher if the mother worked. Agent $j$ with beliefs $\mu_{j, t}, \sigma_{j, t}$ answers no if

$$
\begin{gathered}
\frac{\left(\sum_{k \in \mathbb{J}_{j}} w_{k} / J+\exp \left(\mu_{\omega}\right)\right)^{1-\gamma}}{1-\gamma}+\frac{\beta}{1-\gamma} \exp \left(\left(\mu_{a}-\mu_{j, t}\right)(1-\gamma)+\frac{1}{2}\left(\sigma_{a}^{2}+\sigma_{j, t}^{2}\right)(1-\gamma)^{2}\right) \\
>\frac{\exp \left(\mu_{\omega}(1-\gamma)\right)}{1-\gamma}+\frac{\beta}{1-\gamma} \exp \left(\mu_{a}(1-\gamma)+\frac{1}{2} \sigma_{a}^{2}(1-\gamma)^{2}\right) .
\end{gathered}
$$

We use the mean of all the wage realizations observed by agent $j$ at time $t\left(\sum_{k \in \mathbb{J}_{j}} w_{k} / J\right)$ to estimated agent $j$ 's belief about the average wage among women in the population. ${ }^{4}$

\section{Calibration}

We need to choose parameters for earnings of husbands and wives, utility of leisure, initial beliefs about the value of nurture, a true value of nurture and a number of outcomes to observe each period. These parameters are summarized in table 1. Appendix $\mathrm{C}$ provides more detail on the estimation of the calibration targets.

\footnotetext{
${ }^{4}$ This is an approximation to keep the expression simple. It is not the optimal belief because agent $j$ could also use prior information in forming this belief. But, this problem become intractable because forming a belief about the average wage requires forming a belief about the fraction of women who were nurtured. This requires beliefs about the labor force participation decisions of these women's mothers. Since the mothers' decisions depend on the mothers' beliefs, this requires agent $j$ to form beliefs over the entire past history of signals observed by each family.
} 


\begin{tabular}{lccl}
\hline mean log ability & $\mu_{a}$ & -0.88 & women's earnings distribution \\
std log ability & $\sigma_{a}$ & 0.57 & women's earnings distribution \\
mean log endowment & $\mu_{\omega}$ & -0.28 & average endowment $=1$ \\
std log endowment & $\sigma_{\omega}$ & 0.75 & men's earnings distribution \\
outcomes observed & $\mathrm{J}$ & 3 & Prob $\left(n_{i, t}=n_{i, t-1}\right) 1970-2000$ \\
prior mean $\theta$ & $\mu_{0}$ & 0.04 & unbiased beliefs \\
prior std $\theta$ & $\sigma_{0}$ & 1.38 & 1940 LFP \\
true value of nurture & $\theta$ & 0.04 & children's test scores (NLSY) \\
intertemporal substitution & $\gamma$ & 2 & commonly used \\
\hline
\end{tabular}

Table 1: Parameter values for the simulated model and the calibration targets.

Our strategy is to choose parameters of the earnings and endowment distributions in our model to match the empirical earnings distributions of married women with children under age 5 and their husbands. We match the moments for 1940, the earliest year for which we have the wage distribution data. Since we interpret women's endowment $\omega$ as being the earnings of their husbands, we use a $\log$-normal distribution, $\ln (\omega) \sim N\left(\mu_{\omega}, \sigma_{\omega}^{2}\right)$, which is frequently used to describe earnings. We normalize the average endowment (not in $\operatorname{logs}$ ) to 1 and use $\sigma_{\omega}$ to match the dispersion of 1940 annual wage income of husbands with children under 5 at home. For women, the mean and standard deviation of ability, $\mu_{a}$ and $\sigma_{a}$, match the earnings gap between working women and their husbands and its log standard deviation to data in 1940.

For information-related variables, we don't have such direct observable counterparts. Therefore, we need to infer these variables from properties of the observable participation data. Initial beliefs are assumed to be the same for all women and unbiased, implying $\mu_{0}=\theta$. Uncertainty $\sigma_{0}$ is chosen to match women's 1940 labor force participation. The number of signals observed each period $J$ matches the $42 \%$ average probability of a woman making a different labor participation decision than her mother. We use the 1970-2000 GSS data because matched mother-daughter data is only available for those years. The rationale for matching this moment is that a woman who gets no signals will have the same beliefs as her mother and is likely to choose the same action. A woman who observes many signals will have posterior beliefs potentially far away from the priors she inherited from her mother and will have a higher chance of switching outcomes. A seminar paper in the sociology literature (Marsden 1987) estimates that the average American has three other 
people with whom he/she discusses important issues. Since $J$ includes the woman's observation of her own wage, this implies $J=4$. Section $\mathrm{D}$ explores alternative calibrations. Setting $J=4$ does not appreciably worsen the fit of the model. Introducing biased initial beliefs allows agents to be much less uncertain initially and has a mild slowing effect on learning. ${ }^{5}$

The true value of nurture $\theta$ comes from evidence on the effect of maternal employment on Peabody Individual Achievement Test scores of children (Bernal and Keane 2006) and the correlation between the childhood test scores, educational attainment, and future earnings, estimated by Goldin and Katz (1999). One year of full time maternal employment plus informal day care reduces test scores by roughly 3.4\%. Maternal employment from ages one through six translates into a $4 \%$ drop in children's future annual wages.

The model also needs an initial distribution of signals, which are observations of wages and parental working decisions, in period 1 (1940). Our calibration determines the initial wages, but not the maternal employment decisions. Those come from labor decisions in the previous period (1930). To generate these, we simulate a 1930 period where we fix the labor supply equal to 3 percent, consistent with 1930 Census data and generate a set of signals from those outcomes.

\section{Simulation Results}

We simulate a model with 2000 agents for 10 periods. Agents are born at age 15 with beliefs inherited from their parents. At the end of the first 10-year period outcomes are observed and agents update their beliefs. We assume that each individual observes the potential wage and the employment history of 2 other individuals of the same generation, that are randomly drawn from the distribution. Given the updated beliefs, at age 25 they enter adulthood, have a child and decide whether to participate in the labor market or not. 

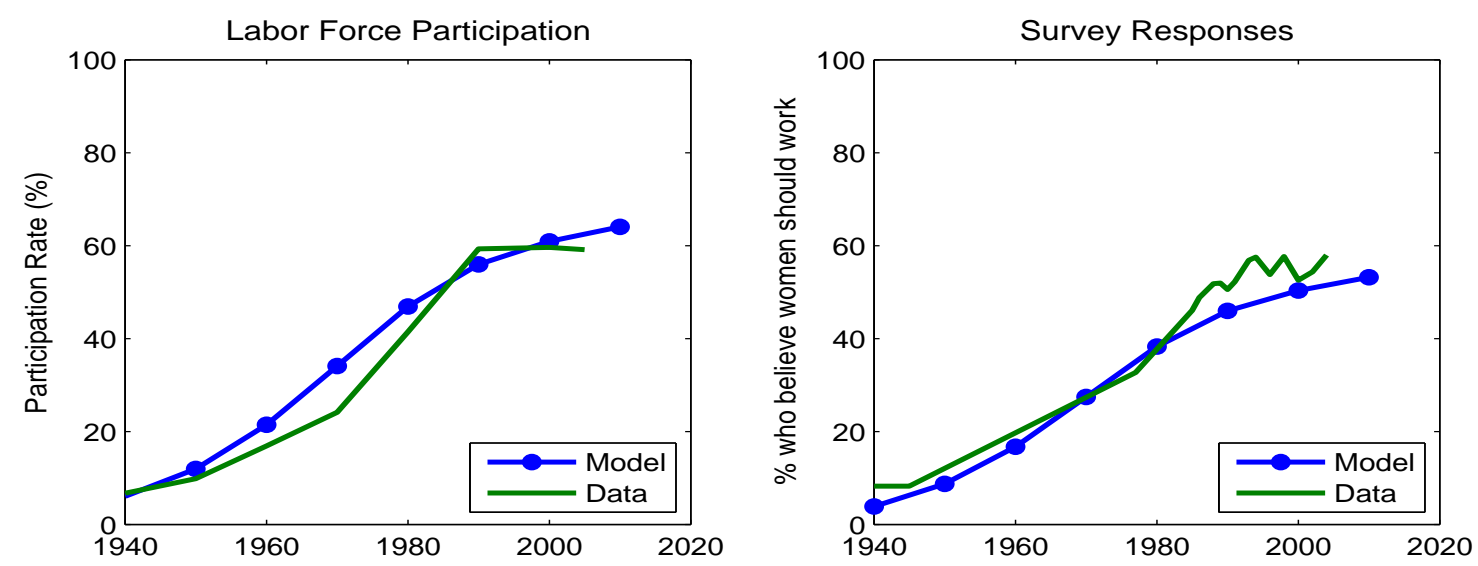

Figure 4: LABOR FORCE PARTICIPATION AND SURVEY RESPONSES IN THE MODEL AND DATA. LFP is the probability a woman participates in the labor force. The rise in survey responses means that women believe labor force participation is less harmful to their children's future outcomes over time.

\subsection{S-shaped dynamics of participation and beliefs}

Figure 4 illustrates the two main predictions of the model. The first (left panel) is the S-shaped rise in labor force participation in the simulated model. If we interpret 1 period as 10 years, then our model matches the realized labor force participation rates reasonably well. Using the model to project forward in time, it forecasts that there will be a $52 \%$ participation rate in 2005 , after which the rate will change very little because learning has mostly converged. In the data, the 2005 participation rate was $59 \%$, meaning that our model under-predicts the increase in labor force participation. At the same time, this leaves some room for factors such as increases in wages and innovations in household technologies to have some effect as well.

The second prediction of the model is that agents' estimates of the value of nurture fall in an S-shaped pattern. Figure 4 (right panel) plots the simulated and actual survey responses taken from (10) for the simulations and from answers to the Census' preschool question for the data. We use the preschool question because it asks specifically about the effect of maternal employment on preschool-age children. The mothers of children below five years of age are the ones whose participation decisions are in the left panel. The drawback of this particular question is that it

\footnotetext{
${ }^{5}$ See Amador and Weill (2006) for an explanation of why more precise initial information slows information diffusion.
} 
misses data before 1977. The calibration appendix describes how we the fework question to infer the earlier data. The result is that the fraction of respondents who support maternal employment and the evolution in that fraction are well-explained by the model.

Taken together, these two graphs illustrate the model's main mechanism: When labor force participation is low, information about the cost of maternal employment on children is scarce, and beliefs change slowly. The slow change in beliefs means a slow rise in the participation rate. As that rate rises, more information is generated by working women whose children's outcomes are observed. Beliefs and participation change at a faster rate. Once information becomes sufficiently abundant, beliefs and labor force participation converge, in unison, to their new steady-state values.

\subsection{Decline in uncertainty}

One of the predictions that distinguishes the learning model from other explanations is that learning entails a reduction in uncertainty. A common proxy for uncertainty is the dispersion in beliefs. The idea is that when there is lots of uncertainty, there is also lots of disagreement about what the right answer is.
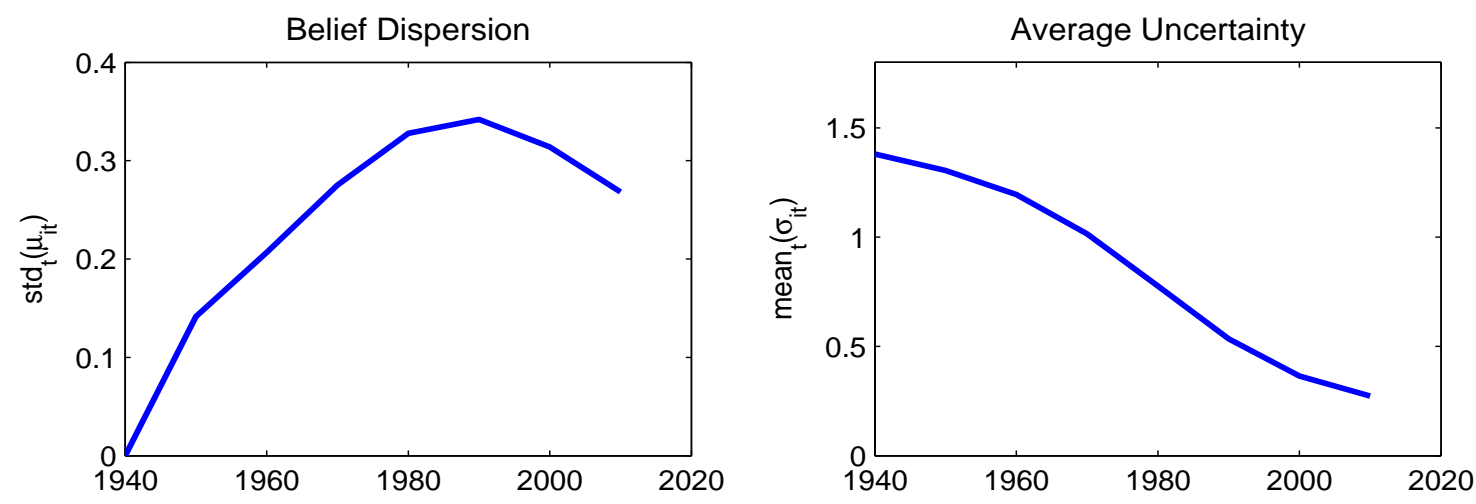

Figure 5: UNCERTAINTY AND BELIEF DISPERSION IN THE SIMULATED MODEL.

Belief dispersion is the cross-sectional standard deviation of the beliefs: $\operatorname{std}\left(\mu_{i, t}\right)$. Uncertainty is the average posterior standard deviation: $\operatorname{mean}\left(\sigma_{i, t}\right)$.

In the model, uncertainty declines monotonically (figure 5, right panel), but belief dispersion, a measure of disagreement, increases then decreases (left panel). Belief dispersion starts out low because we assume that agents have common prior beliefs. Common beliefs, by definition, means 
no dispersion. As women begin working, some agents observe labor market outcomes, while others do not. Furthermore, the inferences that agents make from observing different labor market outcomes vary because the unobserved innate ability of the workers they observe is different. As new information arrives, beliefs diverge. Recall that what slows learning down at the end of the S-curve is that beliefs converge to the truth. Since the true importance of nurture is the same for all agents, their beliefs converge to each other and dispersion falls. The testable prediction here is that, in periods where the increase in labor force participation is slowing down, differences in beliefs should be shrinking. We test this prediction in the next section.

\subsection{Wages and wealth of working women}
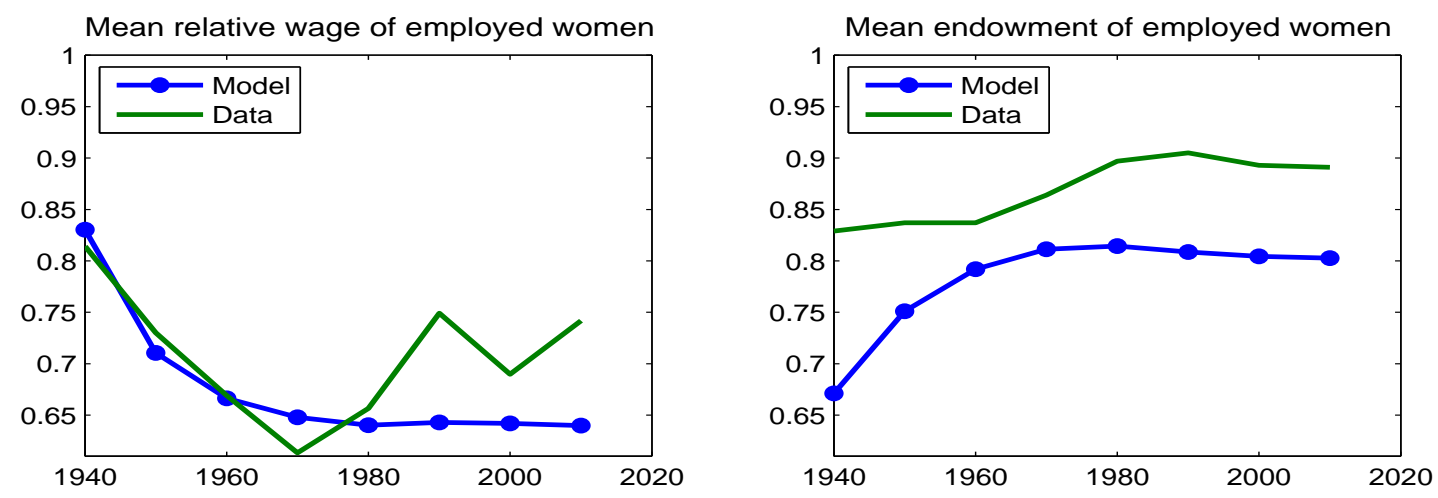

Figure 6: Average Relative WAGE AND ENDOWED WEALth FOR WORKING WOMEN.

Relative wage is the woman's wage divided by her husband's wage $\left(w_{i t} / \omega_{i t}\right)$. Mean relative wage is the relative wage averaged over all employed women. Mean endowment is the average wage for the husband of an employed woman.

Figure 6 shows the mean endowment and the mean wage of the subset of women who choose to participate in the simulated model. We assumed that the unconditional distribution of endowments and abilities is constant. What is changing is the nurture inputs and the selection of women who work. In other words, this is primarily a selection effect.

The finding that women's relative wages declined in the early part of the sample is surprising. But this finding is supported by O'Neill (1984) who documents a widening of the male-female wage gap in the mid-50's to 70's. She attributes it to the same selection effect that operates in our model. What the model does not explain is why women's wages rise, relative to men's after 
1970. Appendix E works out an extended model with occupation choice that can explain this feature of the data. Women face a decision between staying at home, entering a high-wage, highly time-consuming occupation or a low-wage, less demanding job. Over time, women perceive a lower and less uncertain cost of working longer hours and choose careers that pay higher wages. In the calibrated sector choice model, the predictions for total labor force participation are almost identical to the benchmark model. The difference is in the wages - they fall and then rise, like the data.

While learning can offer one explanation for increasing wages, there are obviously other factors external to the model that have contributed to this trend. One of the robustness exercises in appendix D feeds data on trending wages in to the model to see what effect they can have on participation.

The endowment effect is similar. In the data, women working at the beginning of the century are married to poorer husbands than the women that are in the labor force today. The same is true in the model: Early on, women perceive of maternal employment as costly and often choose to work because their husband is poor, making their marginal utility of income high. As the perceived cost of maternal employment falls, women with richer husbands join the labor force. A similar effect works to decrease wages. Early on, only very high-ability women work. As they learn that labor force participation is less detrimental to children, less-able women join the workforce, pushing wages down.

\section{Qualitative Empirical Support}

We examine empirical evidence in support of the indirect predictions of the model. The next section uses these facts in conjunction with our quantitative predictions to distinguish between learning and other theories of labor force participation. 


\subsection{Uncertainty Declined (1972-1996)}

If the learning hypothesis is correct, then uncertainty about the effects of labor force participation on children should decline over time. As beliefs become less uncertain, they are also converging to the truth. This convergence results in falling cross-sectional dispersion of beliefs. This prediction of falling cross-sectional dispersion in beliefs receives mixed support in our survey data.

To measure belief dispersion, we use survey data that is not binary. The dispersion of yes-no answers only reveals how far the average answer is from $50 \%$. Instead, we have three sets of answers that reflect an intensity of preference: preschool, fechild and fefam. All three begin in 1970 and end in 2004. We assign a 1 to strongly agree, 2 to agree, 3 to disagree, and 4 to strongly disagree and take the standard deviation of those replies. In the model, the survey question we pose to agents is a binary one. Therefore, its answers cannot be directly compared. But we can look at the changes in dispersion of beliefs (figure 5). Starting in the 1970's, the dispersion rises slightly and then falls. If we linearly interpolate between decades to get dispersion numbers for 1977 and 2004, we find that the predicted belief dispersion falls by $5.5 \%$.

For our benchmark survey measure of beliefs, preschool, dispersion falls by $2.5 \%$, from 0.80 in 1977 to 0.78 in 2004 . For fechld, dispersion falls by $9.4 \%$, from 0.96 to 0.87 . The exception to this trend is fefam, for which the dispersion rises from 0.81 to 0.86 . However, two features of the fefam data do point to a decline in uncertainty. If we compare the number of agree or disagree responses to the number of strongly agree and strongly disagree responses, the fraction of less certain replies falls from $76 \%$ in 1977 to $71 \%$ in 2002 . Second, the fraction of respondents who reply "I don't know" fell from $1.5 \%$ in 1977 to $1.2 \%$ in 2004 . But, this is a small number of replies.

\subsection{Elasticity of labor supply}

One of the more puzzling changes in female labor force participation in the last 25 years is the decline in labor supply elasticity. Blau and Kahn (2005) document that the elasticity of labor force participation to their own wages decreased by $53 \%$ between 1980 and $2000 .^{6}$ A related fact shows up in our data: In the late 1980's and throughout the 1990's, women's wages continued to increase

\footnotetext{
${ }^{6}$ All elasticity estimates come from Blau and Kahn (2005), table 3, model 4.
} 
and yet labor force participation stagnated. A decline in wage elasticity is predicted by the model (proposition 5). But, the magnitude of this decline in the calibrated model is small. Running a regression similar to Blau and Kahn's on our simulated model delivers a $1.2 \%$ elasticity decline. Similarly, the estimated elasticity of female labor supply to husbands' wages became less negative, falling in magnitude by $47 \%$. The same estimate in the model produces a decline of $2.5 \%$.

One reason for the small change in elasticity has to do with how elasticity is estimated. In theory, proposition 5 varies one woman's wage and calculates the change in probability that she will join the labor force. Empirically, such natural experiments are not observed. Instead, labor economists regress labor force participation rates on wages to infer elasticities. Any non-wage heterogeneity that decreases the covariance of wages and participation will reduce this estimate, even if that added heterogeneity does not make any individual woman less responsive to her wage. The non-wage sources of heterogeneity in the model are endowments and beliefs. Higher belief dispersion reduces estimated elasticity.

In the model, belief dispersion rises in the beginning of the sample because agents start with common priors and then observe different information resulting in different beliefs. This causes own-wage elasticity to drop by $37 \%$ in the first 3 decades. So, the model does produce a large decline in labor supply elasticity. It just does it too early. This has to do with assuming that agents have a common prior in 1940, when the model starts.

In the extended model with occupation choice (appendix E), agents learn almost nothing about the effect of high-intensity careers until the 1970's. Then, as more women join such careers, more signals are generated about the effect of high-intensity maternal employment and the dispersion in beliefs about this new parameter skyrockets in the 70's and 80's. In this model, labor supply elasticity falls by $43 \%$ between 1980 and 2000. It captures most of the decline observed in the data. 


\subsection{Ancestry affects labor choices}

Using data on second generation American women, Fernández and Fogli (2005) show that cultural heritage, measured by country of origin, matters for female labor decisions. ${ }^{7}$ While it could be that childhood or background affect individual preferences, this evidence is also supportive of an information-based theory in which differences in cultural heritage or upbringing expose individuals to different information. By observing different outcomes of previous generations, women from different cultures form different beliefs about the costs of maternal employment.

Likewise, Fernández, Fogli, and Olivetti (2002) show that men who are born and raised by working mothers are more likely to marry a working woman. In our model only women's information affects their labor force participation decision, but it is logical to think that the husband's information is also aggregated when the labor force participation decision is jointly made.

\section{What Learning Adds to Existing Explanations}

While the learning explanation appears to explain the qualitative and quantitative features of the labor force participation data, there are other logical explanations that could potentially do so as well. This section compares the predictions of our model with those of alternative explanations and argues that adding learning can help the existing explanations to better match the data.

\subsection{Rising wages for women}

Wage-based explanations have a hard time reconciling the evolution of female labor force and wages in the last 20 years while wages were rising and labor force participation stagnating. For example, ? use a high wage elasticity to allow changing wages to have a large effect on participation. Although their elasticity falls over time, it stays high enough to generate a continued increase in participation. Our theory (proposition 5) gets the change in labor force participation to slow down. This is true even when we feed in the observed time series of wages for our sample of women. The reason the model succeeds is because its labor supply elasticity falls lower at the end of the sample.

\footnotetext{
${ }^{7}$ Similar results, showing that ancestry affects labor choices can be found in Antecol (2000), Fortin (2005) and Alesina and Giuliano (2007).
} 
Also, the wage-based theory misses cross-sectional differences in participation rates documented in section 1. In particular, it doesn't explain why women with children responded more than women without children. Finally, the wage theory predicts no decline in uncertainty about whether women should participate. If anything, wages have become more uncertain as their dispersion has risen in recent years (Attanasio and Davis (1996), Krueger and Perri (2006)). Increases in wages are obviously an important factor in labor force participation. But learning can modify the predictions of wage-based theories to allow them to match more nuanced features of the data.

\subsection{Availability of child care and new technologies}

Goods and services to assist working mothers encouraged labor force participation (Greenwood and Guner 2005). We can model technological change as a change in the true value of nurture $\theta$. One might argue that as more women entered the labor force, technology reduced the cost of participation and its negative effects on children, accounting for the survey responses. On the other hand, new technologies and child care arise when the demand for them is high, in times when cultural change encourages more women to join the labor force.

One shortcoming of the technology explanation is that it predicts that rich women who can afford new technologies work first. This is at odds with the data (figure 6). Second, it does not explain the fall in labor supply elasticity. If the availability of such goods and services is increasing over time, a second effect should increase the labor supply elasticity: As wages rise, technology and child care become more affordable. Being able to afford them makes working trade off less with a nurturing home environment. Inside the model, this is like being able to sacrifice some labor earnings to reduce $\theta$. That means that not only does an increase in wage increase the benefit to working, it also reduces its cost. This second effect makes labor supply more sensitive to the wage. Finally, adding learning explains why women in the same place, at the same time, make different decisions based on their parents' ethnicity and labor force decisions.

Both the technology and learning mechanisms could be operating simultaneously. Perhaps technological innovations and child care became available when there were enough working mothers demanding them, which reinforced the trend to higher participation. The increased demand could 
come from a change in beliefs about the costs of labor force participation.

\subsection{The pill and endogenous fertility}

Concurrent with the increase in labor force participation was a decline in fertility. Women started having fewer children at a later age. Of course, our empirical analysis is all conditional on women who already have small children. But Goldin and Katz (2002) argue that these women acquired more human capital by postponing motherhood. Thus, the skill composition of our sample has changed. This is undoubtedly true. At the same time, it does not explain most of the increase in labor force participation. That increase started well before the pill was available and continued long after the pill was widespread. Even conditional on having a child and on educational attainment, participation still increased over the course of the century. Furthermore, use of the pill itself was regulated by cultural beliefs about the role women should play in society.

\subsection{Preferences changed}

The hardest alternative explanation to distinguish is a preference change. Perhaps women prefer staying at home when lots of other women stay at home, or preferences change adaptively as a consequence of previous history (Fernández, Fogli, and Olivetti 2002). Three features of the data help us argue that learning is going on. They don't rule out simultaneous changes in preferences, but they support a role for our theory. First, the questions about beliefs in figure 2 questions are not about preferences. They are about the effect of work on children. Second, a change in preferences does not entail a fall in uncertainty. Third, and most importantly, changes in preferences would not cause the labor supply elasticity to fall over time. It is uncertainty, combined with the concavity of the utility function, that can generate the decreased sensitivity of participation to wages that we observe in the data.

Finally, our model can be interpreted as a rational theory of where preference changes come

from. Such a theory is useful because it isolates which preferences matter most for labor force participation, and it offers a testable, systematic way of thinking about why women's preferences have changed. 


\section{Conclusion}

Female labor force participation is highly correlated with reported beliefs about the toll mothers' employment takes on their children. Not only is there a similar trend in these two variables, but they also share a non-linear S-shaped dynamic that other potential explanatory variables do not exhibit. We document these facts and argue that the S-shaped pattern in beliefs comes from Bayesian learning. Women learn about the effect of female employment on children by observing others' upbringing and outcomes. The feedback effect of learning on labor force participation and participation on the set of observable outcomes from which agents can learn generates the S-shaped dynamic. Our learning model delivers indirect testable implications for dispersion in beliefs and labor supply elasticity that are consistent with the data and distinguish our hypothesis from others.

More broadly, the theory provides some insight about how social changes may arise through learning from endogenous information. All kinds of cultural norms are adopted because they are thought to be best practice at the time. If there is no experimentation with alternatives, no new information is learned and the cultural norms stay fixed. Eventually, a few people with extreme preferences or abilities deviate from these norms. In doing so, they provide information that others can observe. This experimentation slowly begins to change beliefs, reducing uncertainty about the desirability of the alternative practice, which encourages others to engage in it. As more people deviate from the cultural norm, learning speeds up, social change quickens and a social revolution takes hold. 


\section{A Technical Appendix: Proofs}

\section{A.1 Proof of proposition 1}

Step 1: Define a cutoff wage $\bar{w}$ such that all women who observe $w_{i, t}>\bar{w}$ choose to join the labor force.

A woman joins the labor force when $E U W_{i t}-E U O_{i t}>0$. Note that $\partial \mathcal{N}_{i, t} / \partial w_{i t}=\left(n_{i t} w_{i t}+\omega_{i t}\right)^{-\gamma}>0$. Since $\mathcal{N}_{i, t}$ is monotonically increasing in the wage $w$, there is a unique $\bar{w}$ for each set of parameters, such that at $w=\bar{w}$, $\mathcal{N}_{i, t}=0$.

Step 2: Describe the probability of labor force participation.

Let $\Phi$ denote the cumulative density function for the unconditional distribution of wages in the population. This is a log-normal c.d.f. Since the lognormal is unbounded and has positive probability on every outcomes, its c.d.f. is therefore strictly increasing in its argument. Then, the probability that a woman participates is $1-\Phi(\bar{w})$, which is then strictly decreasing in $\bar{w}$.

Step 3: The effect of beliefs on labor force participation

Taking the partial derivative of the net utility gain from labor force participation yields $\partial \mathcal{N}_{i, t} / \partial \mu_{i, t}=-\beta$. By the implicit function theorem, $\partial \bar{w} / \partial \mu_{i, t}>0$. Thus, $\partial(1-\Phi(\bar{w})) / \partial \mu_{i, t}=(\partial(1-\Phi(\bar{w})) / \partial \bar{w})\left(\partial \bar{w} / \partial \mu_{i, t}\right)<0$, which completes the proof.

\section{A.2 Proof of proposition 2}

Steps 1 and 2 of the proof are as in appendix A.1.

The benefit to participating is falling in uncertainty: $\partial \mathcal{N}_{i, t} / \partial \sigma_{i, t}=(1-\gamma) \beta \exp \left(\left(\mu_{a}-\mu_{i, t}\right)(1-\gamma)+\frac{1}{2}\left(\sigma_{a}^{2}+\sigma_{i, t}^{2}\right)(1-\gamma)^{2}\right)$. Since $\gamma>1, \beta>0$ by assumption, and the exponential term must be non-negative, this means that $\partial \mathcal{N}_{i, t} / \partial \sigma_{i, t}^{2}<$ 0 . As before, the implicit function theorem tells us that $\partial \bar{w} / \partial \sigma_{i, t}^{2}>0$. Thus, $\partial(1-\Phi(\bar{w})) / \partial \sigma_{i, t}^{2}=(\partial(1-$ $\Phi(\bar{w})) / \partial \bar{w})\left(\partial \bar{w} / \partial \sigma_{i, t}^{2}\right)<0$, which completes the proof.

\section{A.3 Proof of proposition 3: Zero participation is not a steady state}

Proof: For any arbitrary beliefs $\mu_{j t}, \sigma_{j t}$ and endowment $\omega_{j t}$, there is some finite level of ability $a *$ and an associated wage $w *=\exp (a *)$, such that $E U W_{i t}>E U O_{i t}>0, \forall a_{j t} \geq a *$. The fact that $a_{j t}$ is normally distributed means that $\operatorname{Prob}\left(a_{j t} \geq a *\right)>0$ for all finite $a *$. Since woman $j$ enters the labor force whenever $E U W_{i t}>E U O_{i t}>0$, and this happens with positive probability, $n_{j t}=1$ with positive probability. Since this is true for all women $j$, it is also true that $\sum_{j} n_{j t} \geq 1$ with positive probability.

\section{A.4 Proof of proposition 4}

Steps 1 and 2 of the proof are as in appendix A.1.

The benefit to participating is falling in wealth: $\partial \mathcal{N}_{i, t} / \partial \omega_{i, t}=\left(w_{i, t}+\omega_{i, t}\right)^{-\gamma}-\left(\omega_{i, t}\right)^{-\gamma}$. This is negative because $\left(w_{i, t}+\omega_{i, t}\right)>\left(\omega_{i, t}\right)$ holds as long as $w_{i, t}>0$. Since $w_{i, t}$ has a log-normal distribution, it is greater than zero with probability one. As before, the implicit function theorem tells us that $\partial \bar{w} / \partial \omega_{i, t}>0$. Thus, $\partial(1-\Phi(\bar{w})) / \partial \omega_{i, t}=$ $(\partial(1-\Phi(\bar{w})) / \partial \bar{w})\left(\partial \bar{w} / \partial \omega_{i, t}\right)<0$, which completes the proof.

\section{A.5 Proof of proposition 5}

There are two effects of increasing the average wage that show up in elasticity: (1) the direct effect on increasing the number of women whose wages are above the cutoff that determines whether they join the labor force or not; (2) the increase in the expected future wages of children affects the expected cost of joining the labor force. We examine how an increase in uncertainty $\sigma$ affects each part separately, for a woman $(i, t)$. We call the elasticity of this woman's labor supply the conditional elasticity, because it is conditional on her endowment $\omega_{i t}$ and beliefs $\mu_{i t}, \sigma_{i t}$. The last step shows that if $\sigma$ increases the conditional elasticity for every woman, it increases the aggregate labor supply elasticity as well.

Step 1: Direct own-wage effect. The probability that a woman participates is $1-\Phi\left(\bar{w}_{i t}\right)$, which is then strictly decreasing in $\bar{w}_{i t}$, as defined in appendix A.1. Rewrite the cumulative density function as the standard normal c.d.f. $\tilde{\Phi}$ of the $\log$ of $\bar{w}_{i t}$, adjusted by the mean and standard deviation of log wages, $\mu_{w}$ and $\sigma_{w}$. The probability of labor force participation, conditional on having endowment $\omega_{i}$ and beliefs $\mu_{i t}, \sigma_{i t}$ is then $1-\tilde{\Phi}\left(\ln \left(\bar{w}_{i t}\right)-\mu_{w} / \sigma_{w}\right)$. The marginal effect of increasing one's own log wage is the standard normal probability density $\tilde{\phi}\left(\ln \left(\bar{w}_{i t}\right)-\mu_{w} / \sigma_{w}\right)>0$. The conditional elasticity of labor force participation is $\partial \ln (1-\tilde{\Phi}(\cdot)) / \partial \mu_{w}$, since $\mu_{w}$ is the log average wage. The 
conditional elasticity for woman $(i, t)$ to a change in the mean of her own wage is therefore $\tilde{\phi}\left(\ln \left(\bar{w}_{i t}\right)-\mu_{w} / \sigma_{w}\right) /(1-$ $\tilde{\Phi}(\cdot))$, which is a standard normal hazard function, $H\left(\ln \left(\bar{w}_{i t}\right)-\mu_{w} / \sigma_{w}\right)$.

Next, how does the decreasing uncertainty about the effect of nurture change this own-wage elasticity for woman $(i, t)$ over time? Uncertainty affects $\left(1-\tilde{\Phi}\left(\ln \left(\bar{w}_{i t}\right)-\mu_{w} / \sigma_{w}\right)\right)$ through its effect on the cutoff wage $\bar{w}_{i t}$. The proof of proposition A.2 tells us that $\partial \bar{w}_{i t} / \partial \sigma_{i, t}>0$. Therefore, the effect of an increase in uncertainty is given by the cross-partial derivative $\partial^{2} \ln (1-\tilde{\Phi}(\cdot)) / \partial \mu_{w} \partial \bar{w}_{i t}>0$. This is positive because a standard normal hazard function is always increasing in its argument.

Step 2: Indirect effect on children's wages. This effect is the increase in the expected value of $\left(\mu_{a}-\right.$ $\left.n_{i, t} \mu_{i, t}\right)=\mu_{w}$ in the second term of (6). This indirect effect works through the effect of $\mu_{w}$ on $\ln \left(\bar{w}_{i t}\right)$. Putting the two effects together gives us the total conditional elasticity of labor force participation to a change in average wage. Let $C E_{i t}$ represent this conditional elasticity.

$$
\begin{gathered}
C E_{i t}=H\left(\frac{\ln \left(\bar{w}_{i t}\right)-\mu_{w}}{\sigma_{w}}\right)+\frac{\partial \ln (1-\tilde{\Phi}(\cdot))}{\partial \ln \left(\bar{w}_{i t}\right)} \frac{\partial \ln \left(\bar{w}_{i t}\right)}{\partial \mu_{w}} \\
=H\left(\frac{\ln \left(\bar{w}_{i t}\right)-\mu_{w}}{\sigma_{w}}\right)\left(1-\frac{\partial \ln \left(\bar{w}_{i t}\right)}{\partial \mu_{w}}\right)
\end{gathered}
$$

Lastly, we need to compute the derivative of the conditional elasticity with respect to uncertainty $\sigma_{i, t}^{2}$.

$$
\frac{\partial C E_{i t}}{\partial \sigma_{i, t}^{2}}=H\left(\frac{\ln \left(\bar{w}_{i t}\right)-\mu_{w}}{\sigma_{w}}\right)\left(\frac{\partial \ln \left(\bar{w}_{i t}\right)}{\partial \sigma_{i, t}^{2}}\right)\left(1-\frac{\partial \ln \left(\bar{w}_{i t}\right)}{\partial \mu_{w}}\right)-H\left(\frac{\ln \left(\bar{w}_{i t}\right)-\mu_{w}}{\sigma_{w}}\right) \frac{\partial^{2} \ln \left(\bar{w}_{i t}\right)}{\partial \mu_{w} \partial \sigma_{i, t}^{2}} .
$$

Step 1 established that the first term is positive. Since hazard functions are always positive, the last remaining step is to show that $\partial^{2} \ln \left(\bar{w}_{i t}\right) / \partial \mu_{w} \partial \sigma_{i, t}^{2}<0$.

Step 3: Show that $\partial^{2} \ln \left(\bar{w}_{i t}\right) / \partial \mu_{w} \partial \sigma_{i, t}^{2}<0$. Note that

$$
\partial \mathcal{N}_{i, t} / \partial \mu_{w}=\beta \exp \left(\mu_{a}(1-\gamma)+\frac{1}{2} \sigma_{a}^{2}(1-\gamma)^{2}\right)\left(\exp \left((\gamma-1) n_{i, t} \mu_{i, t}+\frac{1}{2} n_{i, t}^{2} \sigma_{i, t}^{2}(1-\gamma)^{2}\right)-1\right) .
$$

This is positive because $(\gamma-1) n_{i, t} \mu_{i, t}+\frac{1}{2} n_{i, t}^{2} \sigma_{i, t}^{2}(1-\gamma)^{2}>0$. This tells us that when expected wages are higher, $\mathcal{N}_{i, t}$, the net benefit of working is higher. This arises because the marginal utility cost of a reduction in expected wages for children is lower if the expected level of those wages is higher. Differentiating this expression again with respect to uncertainty yields:

$$
\frac{\partial^{2} \mathcal{N}_{i, t}}{\partial \mu_{w} \partial \sigma_{i, t}^{2}}=\beta \exp \left(\mu_{a}(1-\gamma)+\frac{1}{2} \sigma_{a}^{2}(1-\gamma)^{2}\right) \exp \left((\gamma-1) n_{i, t} \mu_{i, t}+\frac{1}{2} n_{i, t}^{2} \sigma_{i, t}^{2}(1-\gamma)^{2}\right) \frac{1}{2} n_{i, t}^{2}(1-\gamma)^{2}>0
$$

Note also that $\partial^{2} \mathcal{N}_{i, t} / \partial \mu_{w} \partial w=0$ and $\partial^{2} \mathcal{N}_{i, t} / \partial \sigma_{i, t}^{2} \partial w=0$. Therefore, applying the implicit function rule and differentiating a second time tells us that

$$
\frac{\partial^{2} \ln \left(\bar{w}_{i t}\right)}{\partial \mu_{w} \partial \sigma_{i, t}^{2}}=-\frac{\partial^{2} \mathcal{N}_{i, t} / \partial \mu_{w} \partial \sigma_{i, t}^{2}}{\partial \mathcal{N}_{i, t} / \partial w}+0
$$

Since the numerator is positive and the denominator is positive, the negative sign in front makes the cross-partial negative.

Step 4: Convert conditional to aggregate elasticity. If the conditional elasticity for every woman $(i, t)$ increases when their $\sigma_{i t}$ increases, then when every $\sigma_{i t}$ rises, the aggregate wage elasticity of labor rises as well. The unconditional elasticity is $\int C E_{i t} d F\left(\omega_{i t}, \mu_{i t}, \sigma_{i t}\right)$. Since we can reverse the order of differentiation and integration, the result that the partial derivative of this term is $\int \partial C E_{i t} / \partial \ln \left(\bar{w}_{i t}\right) d F\left(\omega_{i t}, \mu_{i t}, \sigma_{i t}\right)$. Since the term inside the integrand is positive for every $\left(\omega_{i t}, \mu_{i t}, \sigma_{i t}\right)$, the whole expression is positive. 


\section{B Data Description}

\section{B.1 Survey data about beliefs}

Data come from http://webapp.icpsr.umich.edu/GSS/ .

Attitudes We have 6 measures for individuals' attitudes toward women working that have a time series dimension.

fehome Women should take care of running their homes and leave running the country up to men. (AGREE=1, DISAGREE $=2$, NOT $\mathrm{SURE}=8$, NO $\mathrm{ANSWER}=9, \mathrm{NA}=0$ ). We generate a dummy variable fehome=1 if $\mathrm{FEHOME}=1$ and $=0$ if $\mathrm{FEHOME}=2$. exclude observations for which $\mathrm{FEHOME}=0$ or FEHOME $>2$.

The data span 1974-1998, with nine missing years. There are between 890 and 1884 responses per year, with 16 years of observations, for a total 22,538 data points. The fraction of respondents who agree ranges from $38 \%$ in 1977 to $14 \%$ in 1995 .

fework Do you approve or disapprove of a married woman earning money in business or industry if she has a husband capable of supporting her? (AGREE=1, DISAGREE=2, NOT SURE=8, NO ANSWER=9, NA=0). We generate dummy variable fework same as for fehome.

The data span 1972-1998, with ten missing years, for a total of 17 years with observations. There are between 902 and 1,933 responses per year, and 24,401 total observations. The fraction of respondents who agree ranges from $48 \%$ in 1972 to $37 \%$ in 1996.

fechld A working mother can establish just as warm and secure a relationship with her children as a mother who does not work. (STRONGLY AGREE=1, AGREE=2, DISAGREE=3, STRONGLY DISAGREE=4, DON'T $\mathrm{KNOW}=8, \mathrm{NO} A N S W E R=9, \mathrm{NA}=0$ ). We use this variable as is, except observations with $\mathrm{FECHLD}=0$ and FECHLD $>4$ which we treat as missing.

There is one set of observations in 1977, and then from 1995-2004, at least every two years, for a total of 14 years in which data are available. There are between 897 and 1,948 responses per year, totalling 19,270 observations. The average reply ranges from 2.5 in 1977 to 2.1 in 1994 .

preschool A preschool child is likely to suffer if his or her mother works. (STRONGLY AGREE=1, AGREE=2, DISAGREE=3, STRONGLY DISAGREE=4, DON'T KNOW=8, NO ANSWER=9, NA=0). The only modification we make to this variable is to treat observations with preschool $=0$ and preschool $>4$ as missing.

There is one set of observations in 1977, and then from 1995-2004, at least every two years, for a total of 14 years in which data are available. There are between 890 and 2,344 responses per year, totalling 19,005 observations. The average reply ranges from 2.2 in 1977 to 2.6 in 2004.

fefam It is much better for everyone involved if the man is the achiever outside the home and the woman takes care of the home and family. (STRONGLY AGREE=1, AGREE=2, DISAGREE=3, STRONGLY DISAGREE=4, DON'T KNOW=8, NO ANSWER $=9, \mathrm{NA}=0$ ). The only modification we make to this variable is to treat observations with FEFAM $=0$ and $\mathrm{FEFAM}>4$ as missing.

There is one set of observations in 1977, and then from 1995-2004, at least every two years, for a total of 14 years in which data are available. There are between 894 and 2,353 responses per year, totalling 19,024 observations. The average reply ranges from 2.2 in 1977 to 2.6 in 2004.

Acceptance We have 3 measures of acceptance of women working over life cycle. We do not have much of times series dimension (only start in 1988), but they are interesting to show how the presence of a small child is crucial in determining individuals' attitudes.

Attitudes toward women working over life cycle: 3 stages of life cycle corresponding to 3 variables. We have these 3 variables for only 3 years $(1988,1994,2002)$. Not much variation over 14 years, but can be used to make crosssection point. First 9 tables show each variable in each year. Last 3 show the three variables when all observations are pooled across years.

wrknokid Should a woman work outside the home after marrying and before there are children? (1=FULL, $2=\mathrm{PART}, 3=\mathrm{STAY}$ HOME, $8=\mathrm{CAN}$ 'T CHOOSE, $9=\mathrm{NO}$ ANSWER, $0=\mathrm{NA}$ ). Generate variable wrknokid $=$ WRKNOKID but recode WRKNOKID $=0$ and $\mathrm{WRKNOKID}=9$ as missing.

wrkbaby Should a woman work outside the home when there is a child under school age? (1=FULL, 2=PART, $3=$ STAY HOME, $8=$ CAN'T CHOOSE, $9=$ NO ANSWER, $0=$ NA). Generate variable wrkbaby $=$ WRKBABY but recode $\mathrm{WRKBABY}=0$ and $\mathrm{WRKBABY}=9$ as missing. 
wrksch Should a woman work outside the home after the youngest child starts school? (1=FULL, 2=PART, $3=$ STAY HOME, $8=$ CAN'T CHOOSE, $9=$ NO ANSWER, $0=$ NA). Generate variable wrksch $=$ WRKSCH but recode $\mathrm{WRKSCH}=0$ and $\mathrm{WRKSCH}=9$ as missing.

Pre-1972 Data The attitudes data from GSS begin only in 1972. However, the increasing speed of female entry in the labor force (start of the S) precedes that date. To establish the contemporaneous S-shaped evolution of beliefs, it is vital to have more historical data.

We have one measure of beliefs that is collected infrequently, since the 1930's. That is FEWORK. This data are from IPOLL databank, maintained by the Roper Center for Public Opinion Research. Unfortunately, the phrasing of the questions differs slightly over time. We describe below the questions and the replies.

August 1936 The Gallup Poll asked: "Should a married woman earn money if she has a husband capable of supporting her?" $18 \%$ said yes, $82 \%$ no. No uncertain or no response entries were allowed.

October 1938 The Gallup Poll asked: "Do you approve of a married woman earning money in business or industry if she has a husband capable of supporting her?" $22 \%$ approve, $78 \%$ disapprove.

November 1945 The Gallup Poll (AIPO) asked: "Do you approve or disapprove of a married woman holding a job in business and industry if her husband is able to support her?" $62 \%$ disapprove, $18 \%$ approve. The rest of the replies are miscellaneous open answers (e.g., if she has a good job, if she has no children, etc.).

June 1970 The Gallup Poll asked: "Do you approve of a married woman earning money in business or industry if she has a husband capable of supporting her?" $60 \%$ approve, $36 \%$ disapprove, $4 \%$ do not know.

Inferring pre-1977 preschool answers Figure 4 plots survey responses that are preschool replies from 1977-2004. Before 1967, the only beliefs series we have is fework. There are 3 observations available before 1967 and then regular observations starting in 1970. For each of the pre-1977 observations, we compute the growth rate from one data point to the next. Then, we apply these same growth rates to project our preschool data back from 1977 to the earlier observations. We believe that using one series to infer another is a reasonably accurate procedure because for years in which both survey questions are asked, the correlation in the replies is $74 \%$.

\section{B.2 Labor force participation and wage data}

The wages data come from IPUMS (Integrated Public Use Microdata Series). It covers 1920-2005. It is every 10 years until 2000, and yearly thereafter. The data are a 1-in-100 national random sample of the population until 2000. After 2000, it is the American Community Survey 2001 sample: a 1-in-232 (approximately) national random sample of the population. We used only data on white women who are not agricultural workers and live with family members in their household: (race $=1$, gq=1, farm $=1$, sex $=2$, excluding occ $=810,820,830,840,123,100$ ). Residents of Hawaii (statefip=15) and Alaska (statefip=2) are excluded.

Labor Force Observations are dropped if the occupation is in agriculture or the respondent lives on a farm or in an institution. Ages range from 25-54. They are white, married women with spouse present and at least one child under age 5 living in the household. Data are weighted using perwt (sample weights from census). There are no missing labor force observations.

Wages Data start in 1940. (Inctot and incwage start in 1940.) We deflated wages using the consumer price index (Series Id: CUUR0000SA0). The base year is $1982-84=100$. Note that since the survey always asks about the previous year's wages, the 1940 wage data are really about 1939 wages.

We make three modifications to these data. First, we recode the labor force variable and the empstat (employment status) variable as missing value if labforce $=0$ or empstat $=0$, meaning that the answer was $\mathrm{N} / \mathrm{A}$. Second, to account for the top-coding of the income variable, we multiply the top-coded values of INCWAGE (wage income) by a factor of 1.4. Finally, we take the log of each woman's wage, then average across women.

Correcting sample bias There are two issues of sample bias. The first is the standard issue that the census is not perfectly representative. The standard solution to this problem is to use the weights that the census provides on the frequency of various characteristics in the population. We weight all moments by the censusprovided variable perwt. The second issue arises only for 1950 data. The weeks worked and income variables are called "sample line" items in 1950 which means that they were collected only for 1 in 330 respondents. Therefore, we use a different weight "slwt" in 1950. When we look at husband's characteristics in 1950, we weight the husband's income using the women's weight perwt, so that the moments of husbands' wages are 
the endowments of "representative" women. This is equivalent to restricting the sample to only sample line individuals since they are a flat sample in the population.

Dropped observations Also, since working FTYR this year is no guarantee of having worked the year before,and since the earnings refer to the previous year, we also condition on having positive earnings in the previous year for both men and women.

Other data issues We take care of inflation by using CPI (Series Id: CUUR0000SA0), base year 1982-84=100. We recode weeks and hours worked by assigning midpoints We generate a dummy FTYR $=1$ if (weekworkrec $>=50$ and hourworkrec $>=40$ ) We need to condition for women to work full time year around because otherwise we find an incredibly large difference between men and women annual earnings due to the large difference in their labor supply.

Hours and weeks worked The weeks worked variable (WKSWORK2) is an indicator variable that describes which interval the respondent's answer fell in. We replace each indicator with the middle point of the reported interval. We do the same for hours worked (hrswork2). The reporting procedure changes in 1980. From 1980 on, we used the reported average hours per week (UHRSWORK).

Full time This is a dummy variable that indicates if two conditions are satisfied: 1) hrswork2 recoded $\geq 40$, meaning that the worker worked at least 40 hours per week; and 2) WKSWORK2 recoded $\geq 50$, meaning that the woman reports being employed for at least 50 weeks.

\section{Calibration Details}

Throughout, we look at women 25-54, with their own child younger than 5 living in the household. We use individuals not living in institution, not living in farm, not working in agriculture and white.

Abilities The distribution of women's abilities is constructed so that their wages in the model match the distribution of women's wages in the 1940 census data. $\sigma_{a}=.55$ is the standard deviation of $\log$ ability and $\mu_{a}=$ $\ln ($ earnings gap $)-\left(\sigma_{a}^{2}\right) / 2$ is the mean of $\log$ ability. These parameters match the initial ratio between average earnings of working women to average earnings of all husbands ( 0.4 in the data) and to match the standard deviation of log earnings of women in the data (1.08 in the data).

Selection effects in the model The distribution of observed wages in the data needs to be matched with the distribution of wages for employed women in the model. Employed women are not a representative sample. They are disproportionately high-skill women. The calibration deals with this issue by matching the unrepresentative sample in the data to the same unrepresentative sample in the model. In other words, we use the model to back out how much selection bias there is.

Endowment distribution Data come from the census. We use wages in 1940 (first available year). From this, we construct two pools of matched data: One is only married women; the other is their husbands.

The log endowment is normal. For these two sets of wage data, we take the log of wages over previous year. For husbands, mean $(\log$ incwage_husb $)=7.043089$ and std(log_incwage_husb) $=.7348059$. Therefore, we set $\sigma_{\omega}=0.73$. We choose the mean $\log$ endowment $\mu_{\omega}=-\left(\sigma_{\omega}^{2}\right) / 2$ such that mean endowment is normalized to 1 .

Initial labor force participation We need a period 0 participation rate that determines the period 1 wage distribution of women and a period 1 participation rate to start the simulation. Period zero $\mathrm{FLFP}=3 \%$, period one $\mathrm{FLFP}=6 \%$. These are given from Census 1930 and 1940 for women, married, white, not living in farms, not living in institutions, age 25-45 with a child younger than 5 living in the household.

True value of nurture To calibrate the $\theta$ parameter, we use micro evidence on the effect of maternal employment on the future earnings of children. Our evidence on the effect of maternal employment comes from the National Longitudinal Survey of Youth (NLSY), in particular the Peabody Picture Vocabulary Test (PPVT) at age 4 and the Peabody Individual Achievement Test (PIAT) for math and reading recognition scores measured at age 5 and 6 . One year of full time maternal employment plus informal day care reduces test scores by roughly $3.4 \%$ (Bernal and Keane 2006). If a mother works from one year after birth until age six, these five years of employment translate in to a score reduction of $17 \%$.

The childhood test scores are significantly correlated with educational attainment at 18 . A $1 \%$ increase in the math at age 6 is associated with .019 years of additional schooling. A 1\% increase in the reading test score at age 6 is associated with .025 additional school years. Therefore, five years of maternal employment translates into between $0.32\left(17^{*} .019\right)$ and $0.42\left(17^{*} .025\right)$ fewer years of school. 

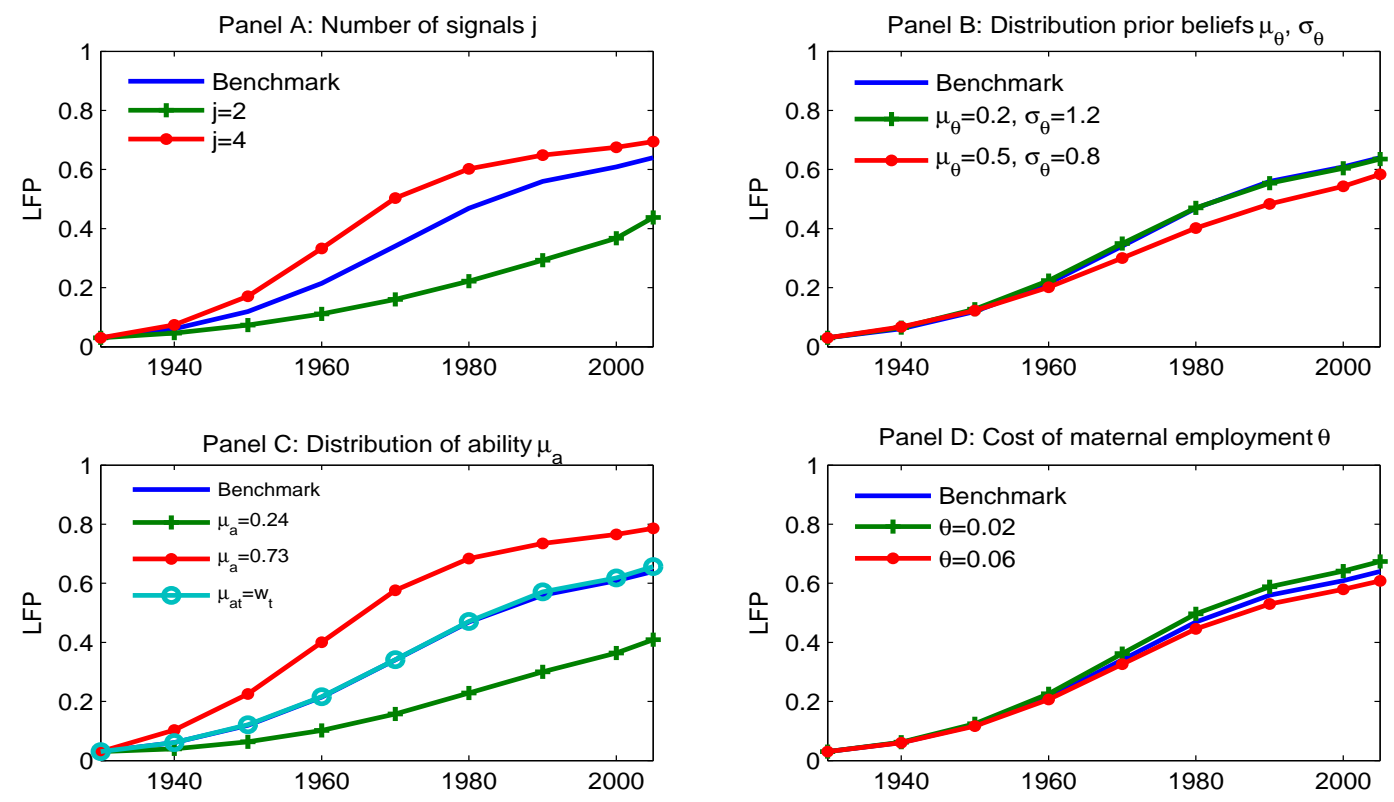

Figure 7: SEnsitivity of LABOR FORCE PREDiCtions TO CHANGES IN PARAMETER VALUES.

The final step is to multiply the change in educational attainment by the returns to a college education. We use the returns to a year of college from 1940 to 1995 from Goldin and Katz (1999). Their estimates are the composition-adjusted log weekly wage for full-time/full-year, non agricultural, white males. Those estimates are $0.1,0.077,0.091,0.099,0.089,0.124$, and 0.129 for the years $1939,1949,1959,1969,1979,1989$, and 1995 . The average return to a year of college is $10 \%$. Since maternal employment reduces education by $0.32-0.42$ years, the expected loss in terms of foregone yearly log earnings is about $4 \%$, or $\theta=0.04$.

Number of signals $J$ is calibrated to the probability that a mother and daughter make the same participation choice. This probability comes from GSS data on married women with children under six who report that they work either full-time or are homemakers and who reported whether their mother worked for at least one year after having children and before they were six years of age.

\section{Robustness Checks}

We explore the sensitivity of model outcomes to changes in four key sets of calibrated parameters.

Number of signals Since the number of signals is not something we can directly observe, it is important that our results not be too sensitive to it. Increasing the number of signals to 4 or decreasing it to 2 either speeds up or slows down learning. This can be seen in the steeper or flatter S-shapes in panel (a). Table 2 shows that the number of signals has mild effects on initial endowments and wages. These initial effects arise because more signals make agents beliefs initially more different. Differences in beliefs, rather than differences in endowments or abilities then becomes a more important determinant of the participation decision. Since selection effects drive the average wage and endowment of working women, the number of signals affects this. The effect is mild. The number of signals has no effect on the ending endowment of wage.

Initial mean and variance One particularly controversial assumption is that initial beliefs are unbiased $\left(\mu_{0}=\theta\right)$. This is dubious in part because our survey evidence suggests otherwise. The fact the respondents report less harm to children from maternal employment later in the sample suggests that average beliefs about $\theta$ started out higher and then fell. 


\begin{tabular}{lc|cccc} 
Model & $\begin{array}{c}\text { parameter } \\
\text { value }\end{array}$ & $\begin{array}{c}\text { starting } \\
\text { wage }\end{array}$ & $\begin{array}{c}\text { ending } \\
\text { wage }\end{array}$ & $\begin{array}{c}\text { starting } \\
\text { endowment }\end{array}$ & $\begin{array}{c}\text { ending } \\
\text { endowment }\end{array}$ \\
\hline Few signals & $J=2$ & 0.58 & 0.52 & 0.61 & 0.80 \\
More signals & $J=4$ & 0.55 & 0.51 & 0.70 & 0.80 \\
Biased beliefs & $\mu_{0}=.2, \sigma_{0}=1.2$ & 0.57 & 0.51 & 0.63 & 0.80 \\
Biased beliefs & $\mu_{0}=.5, \sigma_{0}=.8$ & 0.58 & 0.52 & 0.49 & 0.77 \\
High ability & $\mu_{a}=0.73$ & 0.83 & 0.75 & 0.52 & 0.82 \\
Low ability & $\mu_{a}=0.24$ & 0.28 & 0.26 & 0.90 & 0.86 \\
Calibrated wage & $\mu_{a}$ changes & 0.56 & 0.59 & 0.68 & 0.80 \\
High nurture & $\theta=0.06$ & 0.56 & 0.51 & 0.67 & 0.79 \\
Low nurture & $\theta=0.02$ & 0.56 & 0.52 & 0.68 & 0.82 \\
\hline Benchmark & & 0.56 & 0.51 & 0.67 & 0.80
\end{tabular}

Table 2: Sensitivity of wage and endowment predictions to parameter changes.

We explore different $\mu_{0}$ and $\sigma_{0}$ pairs such that 1940 labor force participation still matches its empirical value. That restricts the set of initial mean beliefs considerably. The upper bound is given by the $\mu_{0}$ that delivers $6.7 \%$ initial participation with no uncertainty $\left(\sigma_{0}=0\right)$. That upper bound is $\mu_{0}=0.64$. Given that we want to explore a situation were agents over-estimate the cost of maternal employment, this restricts $\mu_{0}$ to values greater than 0.04. To explore settings where changes in the mean of beliefs, rather than their variance drive most of the change in participation, we start agents out with beliefs $\mu_{0}=0.2, \sigma_{0}=1.2$, and with a more extreme bias, $\mu_{0}=0.5, \sigma_{0}=0.8$. The moderate bias in beliefs has so little effect on labor force participation that the $\mu_{0}=0.2$ line in panel b completely obscures the line plotted underneath it for the benchmark model. Starting agents out with a high degree of certainty that their initial beliefs are right does have an effect. It makes them slower to learn. But, even when we make initial beliefs about $\theta$ and order of magnitude larger than the truth, the effects on the labor force participation, wages and endowments is not dramatic.

Mean of ability / wages We do three exercises to explore the role of the ability distribution. The first two are straightforward: move the mean of the ability distribution $\left(\exp \left(\mu_{a}\right)\right) 50 \%$ up and down. The results are labeled high ability and low ability.

When women have higher ability, on average, they are more likely to join the labor force and earn higher wages when they work. The effect on participation rates is large, telling us that our results are sensitive to our ability distribution. However, it is comforting that wages are even more sensitive to the mean of ability. This tells us that a given wage distribution provides precise information about what the right ability distribution is.

Time-varying ability distribution The third ability-distribution exercise explores what role empirical changes in wages plays in determining participation. This is the same benchmark model, but a change in the calibration strategy. Instead of assuming that the distributions of endowments and abilities of women are changing overtime, we calibrate a distribution of endowments and of abilities for each decade. The endowment distribution mean and variance comes from the census data in each decade on married men's wages. The distribution of female abilities is calibrated so that wages for working women in the model have the same mean and standard deviation as in the data, for each decade.

Labor force participation is roughly the same with or without exogenous wage increases in 1940 and in 2010. The main difference is that women with exogenous wage changes start participating more slowly because their husbands' wages are increasing rapidly in the 50's, 60's and 70's. Then, labor force participation takes off in the 1970's and 80's. This more steeply-sloped s-shape is more consistent with the data.

True value of nurture We explore two alternative true values of nurture - one that is $50 \%$ higher and one that is $50 \%$ lower than out initial estimate. These changes have small effects of the ending labor force participation rate. They have no effect on wages or endowments. 


\section{E Extension: A Model with Occupation Choice}

The prediction that women's wages should decrease over time is squarely at odds with the data. In this section, we argue that this is not a problem with a learning explanation; it is a problem with assuming women have only one career choice. Allowing women the option to participate in a highly time-intensive but high-wage career, to have a normal career, or to nurture children, results in more women choosing the high-wage career over time. As the composition of career choices changes, wages rise.

The timing, the number of agents and preferences are the same as in the standard model. What is differs is that a woman has an additional career option. If she chooses a high-intensity career, she gets a known multiple $\tilde{w}>1$ of her baseline wage, but may further compromise her ability to nurture her child. Agents learn about two unknown parameters: the value of nurture $\theta$ and the toll on a child of high-intensity maternal employment $\tilde{\theta}$.

The budget constraint of the individual from family $i$ born at time $t-1$ is

$$
c_{i t}=\left(n_{i t}+h_{i t} \tilde{w}\right) w_{i t}+\omega_{i t}
$$

where $h_{i t} \in\{0,1\}$ indicates the choice of a high-intensity career; $\omega_{i t}$ is an endowment which could represent a spouse's income, and $n_{i t} \in\{0,1\}$ is the choice to join a low-intensity career. If the agent works in the labor force, $n_{i t}=1$. If she works in a high intensity career, $h_{i t}=1$. A woman can only have one career: $n_{i t}+h_{i t} \leq 1$.

As before, endowed ability is $a_{i, t} \sim N\left(\mu_{a}, \sigma_{a}^{2}\right)$. If a mother stays home with her child, the child's full natural ability is achieved. If the mother chooses a low-intensity career, some unknown amount $\theta$ of the child's ability will be lost; for a high-intensity career, the loss is $\tilde{\theta}>\theta$. Wages depend exponentially on ability:

$$
w_{i, t}=\exp \left(a_{i, t}-n_{i, t-1} \theta-h_{i, t-1} \tilde{\theta}\right)
$$

Information Sets The constants $\theta$ and $\tilde{\theta}$ are not known when making labor supply decisions. In the first generation, initial beliefs are $\theta \sim N\left(\mu_{0}, \sigma_{0}^{2}\right)$ and $\tilde{\theta} \sim N\left(\tilde{\mu}_{0}, \tilde{\sigma}_{0}^{2}\right)$. The errors in beliefs $\left(\mu_{0}-\theta\right)$ and $(\tilde{\mu}-\tilde{\theta})$ are independent. We assume that the high-intensity career is initially thought to be more detrimental to children: $\tilde{\mu}_{0}>\mu_{0}$.

Each generation updates these beliefs by observing wages and nurturing decisions for themselves and for the same set $\mathbb{J}_{i}$ of peers as in the original model. Ability $a$ is never observed so that neither $\theta$, nor $\tilde{\theta}$ can ever be perfectly inferred from the wage. An important feature of (12) is that a wage is only informative about $\tilde{\theta}$ if the worker's mother had an intense career.

Bayesian updating with $J$ signals is equivalent to running the following regression of children's potential wages on mothers' labor choices

$$
W_{i t}-\mu_{a}=N_{i t} \theta+H_{i t} \tilde{\theta}+\varepsilon_{i t}
$$

where $W_{i t}, N_{i t}$ and $H_{i t}$ are $J \times 1$ vectors $\left\{\log w_{j, t}\right\}_{j \in \mathbb{J}_{i}},\left\{n_{i, t-1}\right\}_{j \in \mathbb{J}_{i}}$ and $\left\{h_{i, t-1}\right\}_{j \in \mathbb{J}_{i}}$. Then, agents form a linear combination of the OLS-estimated $\hat{\theta}$ or $\tilde{\theta}$ and the prior beliefs $\mu_{t}, \tilde{\mu}_{t}$. Let $\bar{h}_{i, t}$ be the sum of the high-intensity careers

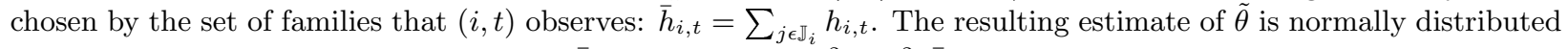
with mean $\tilde{\mu}_{i, t}=\sum_{j \epsilon \mathbb{J}_{i}}\left(\log w_{j, t}-\mu_{a}\right) h_{j, t} / \bar{h}_{i, t}$ and variance $\tilde{\sigma}^{2}=\sigma_{a}^{2} / \bar{h}_{i, t}$.

\section{Equilibrium}

1. Beliefs $\theta \sim N\left(\mu_{i, t}, \sigma_{i, t}^{2}\right)$ and $\tilde{\theta} \sim N\left(\tilde{\mu}_{i, t}, \tilde{\sigma}_{i, t}^{2}\right)$ are formed according to the rules in (4) and (5). Because the unknown components of $\theta$ and $\tilde{\theta}$ are independent, updating occurs separately for high-intensity and lowintensity careers.

2. Substituting (11) and (12) into expected utility produces the following optimization problem. Choose $n_{i t}, h_{i t} \epsilon\{0,1\}$ : $n_{i t}+h_{i t} \leq 1$ to maximize:

$$
\frac{\left(\left(n_{i t}+h_{i t} \tilde{w}_{i t}\right) w_{i t}+\omega_{i t}\right)^{1-\gamma}}{1-\gamma}+\frac{\beta}{1-\gamma} E_{i t}\left[\exp \left(\left(a_{i, t+1}-n_{i t} \theta-h_{i t} \tilde{\theta}\right)(1-\gamma)\right)\right]+L\left(1-n_{i t}-h_{i t}\right) .
$$

3. Distributions of observed wage outcomes indexed by $\mathbb{J}_{i, t}$ are consistent with distribution of optimal labor choices $n_{i,(t-1)}$ and $h_{i,(t-1)}$. 

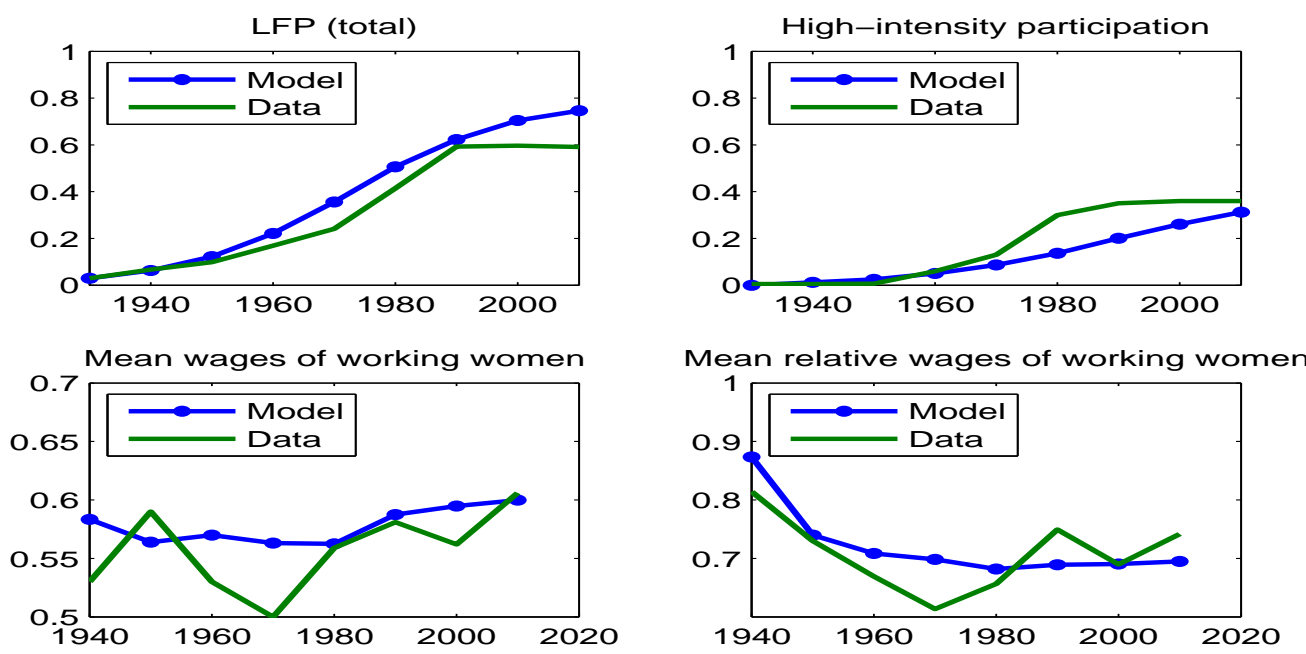

Figure 8: PARTicipation AND WAGES IN THE TWO SECTOR MODEL.

Solving for occupation choice For each possible career choice, we compute the expectation of (13), conditional on time $t$ information $\left(\mu_{i t}, \sigma_{i t}, \tilde{\mu}_{i t}, \tilde{\sigma}_{i t}\right)$. The expected value of staying out of the labor force, $E U O$ and of working in a low-intensity career $E U W$ are given by (7) and (8). The expected utility of a high-intensity career is

$$
E U H_{i t}=\frac{\left(w_{i t} \tilde{w}+\omega_{i t}\right)^{1-\gamma}}{1-\gamma}+\frac{\beta}{1-\gamma} \exp \left(\left(\mu_{a}-\tilde{\mu}_{i, t}\right)(1-\gamma)+\frac{1}{2}\left(\sigma_{a}^{2}+\tilde{\sigma}_{i, t}^{2}\right)(1-\gamma)^{2}\right) .
$$

The optimal career choice for woman $i$ in generation $t$ is: (i) if $E U O_{i t}>E U W_{i t}$ and $E U O_{i t}>E U H_{i t}$, then stay home; (ii) if $E U W_{i t}>E U O_{i t}$ and $E U W_{i t}>E U H_{i t}$, then work in a low-intensity career; (iii) otherwise, if $E U H_{i t}>E U O_{i t}$ and $E U H_{i t}>E U W_{i t}$, then work in a high-intensity career.

Calibration The new model introduces four additional parameters: the true cost $\tilde{\theta}$, the initial beliefs $\tilde{\mu}_{0}$ and $\tilde{\sigma}_{0}$, and the wage premium $\tilde{w}$. For the true nurture cost of high-intensity careers, we calibrate the ratio $\tilde{\theta} / \theta$ to the ratio of hours worked by women in high-intensity to low-intensity professions. Duxbury and Higgins (2003) report that along many dimensions, professional careers are about twice as straining on households. First, the likelihood of having to do overnight job-related travel increases. $19 \%$ of non-professional and $40 \%$ of professional women report spending one night a month away from home. $30 \%$ of non-professional and $60 \%$ of professional women bring work home. Finally, non-professional women do about 11.4 hours of unpaid overtime work per month, while professional women work about 17.7 unpaid hours.

As before, beliefs are unbiased, so that $\tilde{\mu}_{0}=\theta$. We leave the initial uncertainty unchanged: $\tilde{\sigma}_{0}=\sigma_{0}$. The wage premium is the college wage premium for women (Goldin and Katz 2002).

Simulation results In figure 8, labor force participation looks almost identical to the benchmark model. It composition, not its level is changing. The high-intensity participation rises more gradually in the model than in the data, but matches its start and end points well. That data is the number of first year female students in professional schools, divided by the number of first year female college students, reported by Goldin and Katz (2002).

Women's wages, which fell in the benchmark model now fall and then rise. The rise for relative wages is very slight. This happens because the model over-predicts the increase in the husbands' wages. So, the relative wife to husband's wage is suppressed. What will help remedy this problem is to have the wage premium rise. In future work, we plan to calibrate the model so that the wages high-intensity careers refer to professions that require an advanced degree: lawyers, doctors, MBA's, ect. The higher wage premia in these professions could help to match the increase in relative wages. 


\section{References}

Albanesi, S., and C. Olivetri (2006): "Home Production, Market Production and the Gender Wage Gap: Incentives and Expectations," Working Paper.

Alesina, A., And P. Giuliano (2007): "The Power of the Family," Harvard University Working Paper.

Amador, M., and P.-O. Weill (2006): "Learning from Private and Public Observations of Others' Actions," Working Paper.

Antecol, H. (2000): "An Examination of Cross-Country Differences in the Gender Gap in Labor Force Participation Rates," Labour Economics, 7, 409-426.

Attanasio, O., H. Low, and V. Sanchez-Marcos (2006): "Explaining Changes in Female Labour Supply in a Life-Cycle Model," Working Paper.

Attanasio, O. P., and S. J. Davis (1996): "Relative Wage Movements and the Distribution of Consumption," Journal of Political Economy, 104(6), 1127-1262.

Barro, R., and McCleary (2006): "Religion and Economy," Journal of Economic Perspectives, Spring.

Belsky, J. (1988): "The Effects of Infant Day Care Reconsidered," Early Childhood Research Quarterly, 3, 235-272.

Bernal, R., and M. Keane (2006): "Child Care Choices and Childrens Cognitive Achievement: The Case of Single Mothers," Northwestern University, Working Paper.

Bisin, A., And T. Verdier (2000): "Beyond the Melting Pot": Cultural Transmission, Marriage, and the Evolution of Ethnic and Religious Traits," Quarterly Journal of Economics, 115(3), 955-988.

Blau, F., and L. Kahn (2005): "Changes in the Labor Supply Behavior of Married Women: 1980-2000," NBER Working Paper 11230.

Doepke, M., and F. Zilibotti (2007): "Occupational Choice and the Spirit of Capitalism," Working Paper.

Duxbury, L., And C. Higgins (2003): 2001 National Work-Life Conflict Study: Report I. Health Canada.

Fernández, R., And A. Fogli (2005): "An Empirical Investigation of Beliefs, Work and Fertility," NBER Working Paper 11268.

Fernández, R., A. Fogli, and C. Olivetti (2002): "Marrying Your Mom: Preference Transmission and Women's Labor and Education Choices," NBER Working Paper 9234.

Fortin, N. (2005): "Gender Role Attitudes and the Labor Market Outcomes of Women Across OECD Countries," Working Paper. 
Giuliano, P. (2007): "Living Arrangements in Western Europe: Does Cultural Origin Matter?," Journal of the European Economic Association, forthcoming.

Goldin, C. (1990): Understanding the Gender Gap. Oxford University Press.

Goldin, C., And L. Katz (1999): "The Returns to Skill in the United States across the Twentieth Century," NBER Working Paper \# 7126.

(2002): "The Power of the Pill: Oral Contraceptives and Women's Career and Marriage Decisions," Journal of Political Economy, 100, 730-770.

Gourio, F., And P. Noual (2006): "The Marginal Worker and the Aggregate Elasticity of Labor Supply," BU working paper.

Greenwood, J., And N. Guner (2005): "Social Change," Economie d'avant gard, research Report 9, University of Rochester.

Greenwood, J., A. Seshadri, and M. Yorukoglu (2001): "Engines of Liberation," Economie d'avant gard, research Report 2, University of Rochester.

Guiso, L., P. Sapienza, And L. Zingales (2004): "Cultural Biases in Economic Exchange," NBER Working Paper 11005.

HARvey, E. (1999): "Short-Term and Long-Term Effects of Early Parental Employment on Children of the National Longitudinal Survey of Youth," Developmental Psychology, 35(2), 445-459.

Hill, J., J. Waldfogel, J. Brooks-Gunn, and W. Han (2005): "Maternal Employment and Child Development: A Fresh Look Using Newer Methods," Developmental Psychology, 41(6), 833-850.

Jones, L., R. Manuelli, and E. McGrattan (2003): "Why Are Married Women Working So Much?," Research Department Staff Report 317, Federal Reserve Bank of Minneapolis.

Krueger, D., and F. Perri (2006): "Does Income Inequality Lead to Consumption Inequality? Evidence and Theory," Review of Economic Studies, 73(1).

Marsden, P. (1987): "Core Discussion Networks of Americans," American Sociological Review, $52,122-131$.

O’Neill, J. (1984): "The Trend in the Male-Female Wage Gap in the United States," .

Van Nieuwerburgh, S., and L. Veldkamp (2006): "Learning Asymmetries in Real Business Cycles," Journal of Monetary Economics, 53(4), 753-772. 